\title{
Vestibular CCK neurons drive motion-induced malaise
}

Pablo Machuca-Márquez ${ }^{1}$, Laura Sánchez-Benito ${ }^{1,2}$, Fabien Menardy ${ }^{1}$, Andrea Urpi ${ }^{1}$, Isabella Appiah ${ }^{1}$, Richard Palmiter $^{3}$, Elisenda Sanz $z^{1,2^{*}}$, Albert Quintana $^{1,2^{*}}$

\section{Affiliations}

1) Institut de Neurociències, Universitat Autònoma de Barcelona. Bellaterra (Barcelona) 08193. Spain

2) Department of Cell Biology, Physiology, and Immunology

Universitat Autònoma de Barcelona. Bellaterra (Barcelona) 08193. Spain

3) Howard Hughes Medical Institute and Department of Biochemistry, University of

Washington, Seattle WA 98195

*These authors have jointly supervised the work

Corresponding author: elisenda.sanz@uab.cat; albert.quintana@uab.cat 


\section{ABSTRACT}

Passive motion can induce kinetosis (motion sickness, MS) in susceptible individuals. MS is an evolutionary conserved mechanism caused by mismatches between motion-related sensory information and past visual and motion memory, triggering a malaise accompanied by hypolocomotion, hypothermia, hypophagia and aversion to novel foods presented coincidentally. Vestibular nuclei (VN) are critical for the processing of movement input, and motion-induced activation of VN neurons recapitulates MS-related signs. However, the genetic identity of VN neurons mediating MS-related autonomic and aversive responses remains unknown. Here, we identify a glutamatergic vestibular circuitry necessary to elicit MS-related behavioral responses, defining a central role of cholecystokinin (CCK)expressing glutamatergic VN neurons in vestibular-induced malaise. Moreover, we show that CCK VN inputs onto the parabrachial nucleus activate Calca-expressing neurons and are sufficient to establish hypothermia and aversion to novel food. Together, we provide novel insight into the neurobiological regulation of MS, unravelling key genetically defined neural substrates for kinetosis. 


\section{INTRODUCTION}

Motion sickness (MS) is an unpleasant autonomic physiological alteration that occurs in healthy individuals undergoing passive or even illusory motion. MS signs and symptoms include pallor, cold sweating, yawning, retching and vomiting, vertigo, anorexia, drowsiness, and even severe pain ${ }^{1-5}$. MS is highly conserved among species ${ }^{4,6-9}$. Thus, while still debated ${ }^{10}$, it has been posited that MS may provide an evolutionary benefit acting as an early warning system leading to a metabolic expense reduction (hypothermia and drowsiness), expulsion of the toxin (vomiting) and future avoidance (taste aversion) of the ingested substance ${ }^{6}$.

It is widely accepted that MS arises from conflicts between actual visual/vestibular sensory inputs and the expected motion and body position information based on past memories $^{11-13}$. Accordingly, the necessity of a functional vestibular system for the development of MS was identified long ago ${ }^{14,15}$. Movement-related information processed by the vestibular organ in the inner ear is relayed directly to the medullo-pontine vestibular nuclei (VN). Compelling evidence demonstrates that VN neurons are particularly crucial in MS neurobiological regulation by showing that activation of VN neurons through provocative motion reproduced MS-like autonomic alterations in rats and mice ${ }^{16,17}$. In addition, diseases caused by $\mathrm{VN}$ affectation are associated to autonomic dysregulation such as vertigo, nausea, and vomiting ${ }^{18}$.

The role of the $\mathrm{VN}$ in the control of the body orientation system, mainly by means of vestibular reflexes at the ocular, head, neck, and spinal levels, has been amply described ${ }^{19}$. Furthermore, vestibular outputs have been shown to modulate blood pressure with posture change ${ }^{20,21}$. However, how vestibular function governs motion-induced changes in other MSmediated responses, such as hypolocomotion, appetite suppression, loss of body temperature, or acquisition of a conditioned taste aversion (CTA $)^{3,4,8,16,17,22-24}$, is still unknown. In this regard, mapping of neuronal activity after provocative motion has identified 
potential neural substrates for vestibular-induced physiological responses, such as the Nucleus of the Solitary Tract (NTS), paraventricular nucleus of the hypothalamus (PVN), parabrachial nucleus (PBN), central amygdala (CeA), dorsal raphe nucleus, locus coeruleus and area postrema ${ }^{16,17}$. Among them, both the NTS and PBN are known to process visceral sensory input in the brainstem ${ }^{25}$ and receive direct connections from the $\mathrm{VN}^{26,27}$.

Excitatory neurons are the main projection-neuron type in the $\mathrm{VN}^{28}$ and have been suggested to participate in autonomic responses after hypergravity ${ }^{29}$. Furthermore, provocative-motion stimuli activate glutamatergic vesicular glutamate transporter 2 (VGLUT2)-expressing VN neurons that in turn project to downstream nuclei such as the $\mathrm{PBN}^{30-32}$. Thus, we hypothesized that genetically defined, glutamatergic neuronal (sub)populations and circuits in the VN are sufficient and/or necessary to develop MSinduced autonomic regulation and/or aversive learning. To that end, we used cell-typespecific transcriptomics combined with optogenetic and chemogenetic approaches to identify the underlying vestibular circuitry of MS-induced responses.

\section{RESULTS}

\section{Glutamatergic vestibular neurons sustain motion-induced autonomic responses}

Assessment of MS in mice is hindered by the lack of emetic reflex and difficulty to unequivocally identify nausea ${ }^{5,8,33}$. However, behavioral and autonomic signs of MS are consistently observed in mice subjected to rotatory or gravitational paradigms ${ }^{8,16,17}$. Thus, we sought to establish a rotational paradigm sufficient to robustly develop MS-like signs (Fig. 1a). Consistently, four repeated 1-min $4 g$ accelerations (spin stimulation) induced transient hypolocomotion (Fig. 1b and Extended Data Fig. 1a). Furthermore, a significant decrease in food intake was observed in food-deprived mice after spin stimulation 


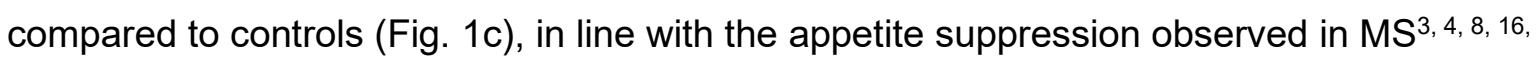

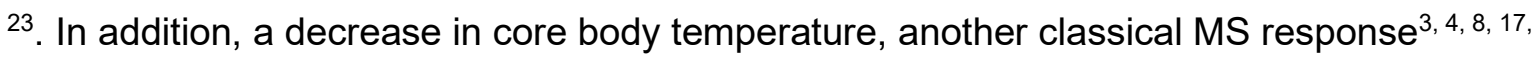
23, 24, was observed after the rotational stimulus compared to controls, with a maximum temperature difference of $4^{\circ} \mathrm{C}$ that occurred $\sim 17.5 \mathrm{~min}$ after rotation onset (Fig. 1d).

With the validity of the rotation paradigm established, we set out to define the neuronal substrate of vestibular-induced, MS-like responses. Excitatory neurons are highly abundant in the $\mathrm{VN}^{28}$ and glutamatergic $\mathrm{VN}$ neurons are activated after provocative motion $^{32}$. Among the different glutamatergic markers, VGLUT2 (encoded by S/c17a6) shows a robust and significant expression in the $\mathrm{VN}^{34}$, and VGLUT2-expressing neurons have been shown to participate in vestibular responses to hypergravity, in contrast to VGAT-expressing inhibitory neurons ${ }^{29}$. Thus, we assessed the necessity of genetically defined glutamatergic VGLUT2-expressing VN (VGLUT2 $\left.{ }^{\mathrm{VN}}\right)$ neurons in eliciting MS behavioral and autonomic responses by bilateral chemogenetic inhibition in a wellcharacterized S/c17a6 $6^{\text {Cre }}$ mouse line ${ }^{35}$ (Fig. 1e). Correct targeting of VGLUT2 ${ }^{\mathrm{VN}}$ neurons expressing hM4Di-mCherry was subsequently verified by immunofluorescence (IF) analysis using an anti-mCherry antibody (Extended Data Fig. 1b). Targeted inhibition of VGLUT2 ${ }^{\mathrm{VN}}$ neurons did not induce significant effects on locomotion prior to spin stimulation (Extended Data Fig. 1c). However, inhibition of VGLUT2 ${ }^{\mathrm{VN}}$ neurons by addition of the clozapine $\mathrm{N}-$ oxide (CNO) ligand prevented spin-induced decreases in ambulatory activity (Fig. 1f), appetite suppression (Fig. 1g) and attenuated the MS-related decrease in body temperature (Fig. 1h). Noteworthy, an initial decrease in body temperature was observed in CNO-injected mice (Fig. 1h), suggesting that other neuronal populations may contribute to the early spin-induced drop in body temperature. These results indicate that VGLUT2 ${ }^{\mathrm{VN}}$ neurons are necessary to promote the development of the MS-like behavioral and autonomic responses elicited by rotational stimulation.

Nauseogenic responses can be obtained after unilateral inner ear caloric 
stimulation ${ }^{36}$. Hence, to test whether VGLUT2 ${ }^{\mathrm{VN}}$ neuronal activation is sufficient to induce MS-like autonomic responses, S/c17a6 ${ }^{\text {Cre }}$ mice received a unilateral injection of an AAV1 expressing Cre-dependent ChR2·YFP (Vglut2 ${ }^{\mathrm{VN}}:$ ChR2 mice; for photoactivation) or a YFP construct (Vglut2 ${ }^{\mathrm{VN}}$ :YFP mice; as control) into the right $\mathrm{VN}$ and an optical fiber was implanted over the injected VN (Fig. 2a). Specific targeting of the viral vector and optical fiber placement were confirmed at the end of the experiment using anti-GFP and anti-GFAP antibodies (Extended Data Fig. 2a). GFP antibodies reveal the transduced cells while the GFAP antibodies reveal astrocyte reactivity resulting from optical fiber implantation. Increasing photostimulation frequencies reduced ambulatory activity in Vglut2 ${ }^{\mathrm{VN}}$ :ChR2 mice relative to controls (Extended Data Fig. 2b). We used a 5-min, 40-Hz, optogeneticstimulation paradigm because we and others have shown VGLUT2 ${ }^{\mathrm{VN}}$ neurons in actively moving mice maintain firing rates of $\sim 40 \mathrm{~Hz}^{37,38}$ (Extended Data Fig. 2b). VGLUT2 ${ }^{\mathrm{VN}}$ neuron optogenetic activation led to a significant decrease in spontaneous ambulatory activity (Fig. $2 b)$, consistent with the results obtained after rotational stimulus. Furthermore, ingestion of their regular, low-calorie chow and water intake after optogenetic VGLUT2 ${ }^{\mathrm{VN}}$ activation were significantly decreased, showing complete suppression for as long as $30 \mathrm{~min}$ after laser onset (Fig. 2c, d). Noteworthy, a recovery in the feeding pattern was observed after presentation of highly palatable, chocolate-flavored, liquid diet to a separate cohort of laserstimulated Vglut2 ${ }^{\mathrm{VN}}: \mathrm{ChR} 2$ mice (Fig. 2e), ruling out physical inability to feed but rather a lack of motivational drive to consume regular chow or water. Core body temperature significantly decreased, with a maximum $3^{\circ} \mathrm{C}$-drop occurring $17.5 \mathrm{~min}$ after laser onset (Fig. 2f). To rule out the possibility that optogenetic-induced loss of core body temperature was due to a reduction in ambulatory activity in Vglut2 ${ }^{\mathrm{VN}}: \mathrm{ChR} 2$ mice, an additional optogenetic stimulation was applied under physical restraint. Under these conditions, core body temperature increased in Vglut2 ${ }^{\mathrm{VN}}$ :YFP mice, likely due to restraint-induced stress responses. However, Vglut2 ${ }^{\mathrm{VN}}:$ ChR2 mice still showed a significant drop in body temperature coincident with 
photostimulation (Fig. 2g). These results highlight a role of VGLUT2 ${ }^{\mathrm{VN}}$ neurons in MS regulation.

\section{Identification of CRH- and CCK-expressing VGLUT2 ${ }^{\mathrm{VN}}$ neuronal subpopulations}

To define VGLUT2 ${ }^{\mathrm{VN}}$-neuron subpopulations, we performed viral vector-mediated RiboTag molecular profiling ${ }^{39-41}$ in VN homogenates of S/c17a6 $6^{\text {Cre }}$ mice injected with a RiboTagexpressing construct (AAV1-DIO-RpI22·HA ${ }^{40}$, Fig. 3a). Transcripts enriched in VGLUT2 ${ }^{\mathrm{VN}}$ neurons were identified by differential expression analysis in RNA samples extracted from the RiboTag immunoprecipitates (IP; containing polysome-associated mRNAs from VGLUT2 ${ }^{\mathrm{VN}}$ neurons) and the input (I) of the immunoprecipitation (containing RNA from all the different cell types in the VN). Data analysis confirmed specific enrichment for Slc17a6 (Vglut2), and depletion for inhibitory neuron (Gad2) and non-neuronal marker transcripts (Cnp, Gfap) in the RiboTag IPs, and revealed significant enrichment for candidate VGLUT2 $^{\mathrm{VN}}$ neuron subpopulation markers such as Cck, Crh, Adcyap1, Gal and Coch (Fig. 3b). Among these, Crh- and Cck-expressing neurons have been shown to be involved in autonomic and nauseogenic responses ${ }^{42,43}$, highlighting the potential relevance of these neuronal populations in VN-mediated MS responses. Subsequent in situ hybridization assays confirmed co-localization of either Crh or Cck with Slc17a6 (Fig 3c, g).

\section{Modulation of vestibular CCK-expressing neurons causes MS-like autonomic responses}

To test the necessity of vestibular Crh- or Cck-expressing neuronal populations $\left(\mathrm{CRH}^{\mathrm{VN}}\right.$ or $\mathrm{CCK}^{\mathrm{VN}}$ neurons, respectively) in the development of MS-like signs, we injected $\mathrm{Crh}^{\mathrm{Cre}}$ or $C c k^{C r e}$ mice bilaterally in the VN with a AAV vector carrying Cre-dependent hM4Di-mCherry (Fig. 3d, h). Chemogenetic inhibition of $\mathrm{CRH}^{\mathrm{VN}}$ neurons did not induce any effect pre- or post-spin on ambulatory activity (Extended Data Fig. 3a and Fig. 3e) or core body 
temperature changes (Fig. 3f) compared to vehicle-treated mice, indicating that they are not necessary to develop rotation-induced autonomic responses. Noteworthy, optogenetic stimulation of $\mathrm{CRH}^{\mathrm{VN}}$ neurons (Extended Data Fig. 3b) induced a marked reduction in locomotion and body temperature (Extended Data Fig. 3c, d), suggesting that this neuronal population is sufficient, but not necessary, to induce MS-like symptoms. On the other hand, bilateral chemogenetic inhibition of $\mathrm{CCK}^{\mathrm{VN}}$ neurons significantly decreased ambulatory activity in the absence of rotational stimulus (Fig. 3i), which led to an inability to move after the spin (Fig. 3j). Thus, $\mathrm{CCK}^{\mathrm{VN}}$ inhibition per se is sufficient to induce locomotor effects. Core body temperature also decreased in the CNO-injected hM4Di group, dropping $>4^{\circ} \mathrm{C}$ compared to vehicle-injected mice (Fig. 3k) and exacerbated by rotational stimulation (Fig. 3I). Subsequently, we performed optogenetic activation of $\mathrm{CCK}^{\mathrm{VN}}$ neurons (Fig. 4a, b), which led to a significant and prolonged decrease in spontaneous ambulatory activity in the openfield test compared to the control animals (Fig. 4c). Similarly, food intake was significantly decreased after photostimulation of $\mathrm{CCK}^{\mathrm{VN}}$ neurons, showing a complete suppression for 35 min, while control animals engaged in feeding almost immediately (Fig. 4d). Optogenetic stimulation of $\mathrm{CCK}^{\mathrm{VN}}$ neurons reduced core temperature $\left(\sim 4.5^{\circ} \mathrm{C}\right)$, occurring 22.5 min after laser onset, in contrast with control mice (Fig. 4e). These results underscore the role of $\mathrm{CCK}^{\mathrm{VN}}$ neuronal activity in mediating MS-like behavioral and autonomic responses.

\section{$\mathrm{CCK}^{\mathrm{VN}}$ neurons send dense projections to the PBN}

Because optogenetic activation of $\mathrm{VGLUT}^{\mathrm{VN}}$ or $\mathrm{CCK}^{\mathrm{VN}}$ neurons elicits similar behavioral responses, we hypothesized that common projection areas between the two populations would underlie these MS-like responses. To elucidate the genetically defined, vestibular circuits involved in these responses, $S / c 17 a 6^{C r e}$ or $C c k^{C r e}$ mice received a unilateral injection of an AAV1 expressing a Cre-dependent synaptophysin. GFP fusion protein ${ }^{44}$ in the right VN to identify both unilateral and contralateral projection regions for each neuronal population 
(Fig. 5a, c). Among the different targeted areas, dense VGLUT2 ${ }^{\mathrm{VN}}$ and $\mathrm{CCK}^{\mathrm{VN}}$ terminals were found in the ipsilateral PBN (Fig. 5b, d), with much less intense projections to the contralateral PBN (data not shown). These results suggested that a Slc17a6- and Cckexpressing vestibulo-parabrachial $\left(\mathrm{CCK}^{\mathrm{VN} \rightarrow \mathrm{PBN}}\right)$ circuit might be relevant in $\mathrm{MS}$.

\section{$\mathrm{CCK}^{\mathrm{VN} \rightarrow \mathrm{PBN}}$ circuit stimulation mediates MS-induced hypothermia}

To ascertain whether the $\mathrm{CCK}^{\mathrm{VN} \rightarrow \mathrm{PBN}}$ circuit plays a role in MS-like behavioral and autonomic symptoms, we optogenetically activated $\mathrm{CCK}^{\mathrm{VN}}$ axon terminals in the PBN by placing the optical fiber-tip over this region in $\mathrm{Cck}^{\mathrm{VN}}$ :ChR2 mice (Fig. 5e). After behavioral testing, the presence of ChR2·YFP-positive terminals and successful optical fiber placement in the PBN was verified (Extended Data Fig. 4a). This analysis also revealed projections of CCK ${ }^{\mathrm{VN}}$ neurons to the NTS (Extended Data Fig. 4b). Behaviorally, optogenetic stimulation of $\mathrm{CCK}^{\mathrm{VN} \rightarrow \mathrm{PBN}}$ fibers did not lead to significant differences in locomotion or food intake (Fig. $5 f$, g). However, a significant decrease in body temperature was observed after optogenetic stimulation of this circuit (Fig. 5h). Overall, these results suggest an involvement of the $\mathrm{CCK}^{\mathrm{VN} \rightarrow \mathrm{PBN}}$ circuit in MS-related body temperature regulation, likely in coordination with $\mathrm{CCK}^{\mathrm{VN}}$ projections to other brain regions.

\section{A $C C K^{\mathrm{VN} \rightarrow \mathrm{PBN}}$ circuit stimulation mediates MS-like CTA response}

MS is known to induce a robust CTA ${ }^{22}$, which has been proposed to be a byproduct of a defense system ${ }^{6}$, and the PBN has been shown to mediate MS-like CTA acquisition ${ }^{45}$. Hence, we asked whether the $\mathrm{CCK}^{\mathrm{VN} \rightarrow \mathrm{PBN}}$ circuit can establish a CTA. We adapted a twobottle CTA test ${ }^{46}$ (Fig. 6a). Two conditioning sessions paired a $5 \%$ sucrose solution with rotational motion, followed by a choice test the next day of water or sucrose. We observed a significant reduction in sucrose preference when sucrose was paired with rotation, compared to controls (Fig. 6b), in agreement with the role of MS establishing a CTA ${ }^{22}$. Pairing sucrose 
with optogenetic activation of the $\mathrm{CCK}^{\mathrm{VN}}$ subpopulation by placing the fiber-optic over either the $\mathrm{VN}$ or the projection to the PBN also significantly decreased sucrose preference when compared to controls (Fig. $6 \mathrm{c}, \mathrm{d}$ ). Pairing of the $5 \%$ sucrose solution to unilateral optogenetic activation of the YFP-control group did not result in CTA. Consistent with these results, inhibition VGLUT2 ${ }^{\mathrm{VN}}$ neurons by expression of hM4Di and administration of CNO prevented spin-induced CTA (Fig. 6e). However, pairing 5\% sucrose solution to unilateral optogenetic activation of VGLUT2 ${ }^{\mathrm{VN}}$ neurons did not result in significant differences between the ChR2 and the YFP group (Fig. 6f). These results reveal that activation of $\mathrm{CCK}^{\mathrm{VN}}$ neurons that project to the PBN is sufficient to develop MS-like CTA and activation of VGLUT2 ${ }^{\mathrm{VN}}$ neurons is necessary for development of MS-induced CTA.

To identify the neuronal population in the PBN receiving inputs from $\mathrm{CCK}^{\mathrm{VN}}$ neurons, we performed double-label ISH assays for Fos (a marker of neuronal activity) and Calca (encodes calcitonin gene-related peptide, CGRP) because these PBN neurons have been implicated in mediating visceral malaise and $\mathrm{CTA}^{44,47,48}$. Photoactivation of $\mathrm{CCK}^{\mathrm{VN}}$ neurons increased the number of Fos positive-cells in the PBN, which colocalized in part to Calcaexpressing neurons (Fig. 6g). Importantly, rotational stimulation also induced Fos in Calcaexpressing cells, supporting a role for this neuronal population in mediating MS-induced CTA (Extended Data Fig. 5a). These results underscore $\mathrm{CCK}^{\mathrm{VN} \rightarrow \mathrm{PBN}}$ activation of CGRP neurons as a key component of MS-induced CTA.

\section{DISCUSSION}

MS has long accompanied and disabled humans. Being described by Hippocrates over 2000 years ago, MS has affected millions of individuals, including historical figures such as Julius Caesar and Charles Darwin ${ }^{3}$. The CNS is thought to compute an MS-triggering sensory 
conflict signal analogously to "toxic shock", eliciting malaise and nausea ${ }^{6,12,24,49}$. Thus, in an evolutionary context, MS responses could represent a proxy for toxicity-induced balance mismatches. Hence, vomiting observed in humans would be a response to evacuate toxic substances, appetite suppression to avoid additional toxic ingestion, hypolocomotion and hypothermia to minimize the metabolism, and CTA to avoid consumption of toxins in the future. However, the neurobiological underpinnings of MS have remained elusive. Our results link VGLUT2 ${ }^{\mathrm{VN}}$ and CCK ${ }^{\mathrm{VN}}$ excitatory neuronal populations to the development of MS-like symptoms in mice. Furthermore, we show that $\mathrm{CCK}^{\mathrm{VN} \rightarrow P B N}$ projections are sufficient to induce hypothermia and CTA, common features of MS, likely through the activation of

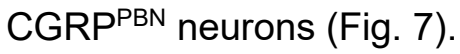

MS is conserved among animal phyla ${ }^{4,6-9}$, but with a high degree of heterogeneity in its behavioral and physiological correlates. Mice do not present an emetic reflex but do present overt physiological and behavioral alterations when exposed to a nauseogenic experience $^{4,17,22,23}$ such as sustained $2 g$ rotational stimuli ${ }^{8,16,17,23,29}$. We show that a rotational stimulus of $4 \mathrm{~min}$ is sufficient to develop robust hypolocomotion, hypophagia, hypothermia, and CTA to a novel food.

The role of the $\mathrm{VN}$ in the development of $\mathrm{MS}$ is well recognized ${ }^{16,17}$. The currently accepted hypothesis is that the vestibular inner ear organs provide a major input for the subsequent computing comparisons between present sensory input (integrated input including vestibular, visual and proprioceptive information) and memory recalled from similar motion situations experienced in the past ${ }^{12,13}$. Rotational stimuli convey information from the semicircular canals mostly onto medial VN (MVN) neurons, leading to nauseogenic responses $^{5,36,50}$. Here we show that optogenetic activation of VGLUT2 ${ }^{\mathrm{VN}}$ neurons that are abundant in the $\mathrm{VN}^{16,28,32,34,51}$ is sufficient to induce MS-like behaviors such as hypolocomotion, hypothermia and hypophagia, in agreement with recent results ${ }^{29}$. Furthermore, our bilateral chemogenetic inhibition experiments show, for the first time, that 
VGLUT2 $^{\mathrm{VN}}$ neurons are necessary for the development of MS responses in a rotational paradigm in mice.

Several excitatory populations have been described in the VN that may be involved in different aspects of vestibular-mediated responses ${ }^{51}$. Using the RiboTag approach ${ }^{39}$ we identified several genetic markers for subpopulations. Our results validate genes $\mathrm{Crh}$ and Adcyap $1^{51}$ and identify new markers for VGLUT2 ${ }^{\mathrm{VN}}$ neurons including Gal, Coch and Cck. We show a differential role for $\mathrm{CCK}^{\mathrm{VN}}$ and $\mathrm{CRH}^{\mathrm{VN}}$ in the appearance of MS-like behaviors. Unilateral optogenetic activation of either $\mathrm{CCK}^{\mathrm{VN}}$ or $\mathrm{CRH}^{\mathrm{VN}}$ neurons is sufficient to induce hypolocomotion, hypothermia and hypophagia. However, $\mathrm{CRH}^{\mathrm{VN}}$ neurons are not necessary for these MS-like responses after a rotational stimulus, indicating they may be upstream of the effector VGLUT2 ${ }^{\mathrm{VN}}$ subpopulation(s). On the other hand, restricted inhibition of CCK ${ }^{\mathrm{VN}}$ neurons significantly decreased ambulatory activity and temperature, even in the absence of a rotational stimulus. Thus, our data show that alterations in the activity of these neurons exert a pivotal role in controlling MS-like behavioral responses. MVN neurons produce endogenous, spontaneous pacemaker activity ${ }^{52}$. Restoration of MVN pacemaker activity is key for MS habituation ${ }^{53}$. Thus, $\mathrm{CCK}^{\mathrm{VN}}$ neurons may contribute to pacemaker activity and variations of their rhythmic firing rate may lead to MS-like symptoms.

We validated dense projections from VGLUT2 ${ }^{\mathrm{VN}}$ and $\mathrm{CCK}^{\mathrm{VN}}$ neurons to the $\mathrm{PBN}^{32}$. The PBN is known to mediate malaise, appetite suppression, lethargy, anxiety, thermoregulation, and CTA ${ }^{25,54}$. Chemogenetic inhibition of VGLUT2 ${ }^{\mathrm{VN}}$ neurons blocked hypothermia and CTA in our MS paradigm. Unilateral optogenetic stimulation of CCK ${ }^{\mathrm{VN}}$ neurons or the projection to the PBN produced hypothermia and robust CTA. However, optogenetic stimulation of VGLUT2 ${ }^{\mathrm{VN}}$ neurons was not sufficient to develop CTA, likely suggesting the existence of opposing VGLUT2 ${ }^{\mathrm{VN}}$ subpopulations. Rotational stimulus and $\mathrm{CCK}^{\mathrm{VN}}$ optogenetic stimulation activated CGRP-expressing, glutamatergic neurons in the lateral PBN, which are known to be involved in malaise, and $\mathrm{CTA}^{25}$, sustaining the 
establishment of aversive taste memories ${ }^{46}$. Thus, we propose that glutamatergic $\mathrm{CCK}^{\mathrm{VN}}$ input onto CGRPPBN neurons mediates MS-induced CTA. Activation of VGLUT2 ${ }^{\mathrm{VN}}$ neurons leads to hypothermia, likely by decreasing sympathetic tone ${ }^{29}$. Recent reports revealed that Pdyn-expressing PBN neurons $\left(\mathrm{Pdyn}^{\mathrm{PBN}}\right)$ regulate hypothermia through projections to the pre-optic area ${ }^{54}$, involved in temperature regulation ${ }^{55}$. Hence, $\mathrm{CCK}^{\mathrm{VN}}$ activation of $\mathrm{Pdyn}^{\mathrm{PBN}}$ neurons might mediate the MS-induced drop in body temperature. $\mathrm{CCK}^{\mathrm{VN} \rightarrow \mathrm{PBN}}$ projections do not seem to participate in MS-induced hypophagia and hypoactivity, even though activation of CGRP ${ }^{P B N}$ neurons is involved in appetite suppression and reduced locomotion ${ }^{25,44}$. Thus, it is likely that $\mathrm{CCK}^{\mathrm{VN}}$ projections to other brain areas may be responsible for these responses. For example, $\mathrm{CCK}^{\mathrm{VN}}$ neurons also project to the NTS where neurons reside that can activate PBN ${ }^{\mathrm{CGRP}}$ neurons to promote anorexia ${ }^{56}$.

Our study underscores a key role for excitatory VGLUT2 ${ }^{\mathrm{VN}}$ and $\mathrm{CCK}^{\mathrm{VN}}$ neurons in MS-related behavioral and physiologic responses. Future studies detailing the behavioral and physiological contribution of other $\mathrm{CCK}^{\mathrm{VN}}$ targets as well as other VGLUT2 ${ }^{\mathrm{VN}}$ subpopulations will provide a complete profile of the neurobiological substrates of MS.

\section{METHODS}

\section{Mice}

The following mouse lines were used in this study: S/c17a6 ${ }^{\text {Cre }}$ (BAC-Vglut2::Cre) ${ }^{35}$ mice were generated by Ole Kiehn. Cck ${ }^{\mathrm{Cre}}$ (CCK-IRES-Cre) and $\mathrm{Crh}^{\mathrm{Cre}}(\mathrm{CRH}-\mathrm{IRES}-\mathrm{Cre})^{57}$ mice were obtained from The Jackson Laboratory (Bar Harbor, ME. Stock No: 012706 and 012704 , respectively). Mice were group-housed with a $12: 12 \mathrm{~h}$ light:dark cycle at $22^{\circ} \mathrm{C}$, with ad libitum access to rodent chow (Teklad Global Rodent Diet \#2014S; Envigo) and water, unless otherwise stated. Sex and age-balanced groups of 2- to 7-month-old mice were used across 
all experimental procedures. No sex differences were observed. After surgeries, animals were individually housed until the end of all experimental procedures. Sample sizes were determined using power analyses. Number of animals used per experiment $(n)$ are detailed in figure legends. All mice were on a C57BL/6J background after backcrossing for at least 10 generations. All experiments were conducted following the recommendations in the Guide for the Care and Use of Laboratory Animals and were approved by the Animal Care and Use Committee of the Universitat Autònoma de Barcelona and the Generalitat de Catalunya.

\section{Rotational stimulus}

Prior to rotational stimulation, animals were habituated to physical restraint for 4 min using a 50-mL conical tube coupled to a custom-made rotary device (external radius: $10.5 \mathrm{~cm}$; internal radius from mouse head: $5 \mathrm{~cm}$. Rotation multiplier: x3.6). Afterwards, rotational (four repeated 1-min, 4- $g$ accelerations) or control (4 min with no rotation) stimuli were applied, unless otherwise stated. 1-min accelerations included $55 \mathrm{~s}$ of rotation plus $5 \mathrm{~s}$ break until full stop. To achieve $4 \mathrm{~g}$ accelerations, $75 \mathrm{rpm}$ were applied.

\section{Behavioral assays}

Each animal was subjected to an open-field test, followed by food intake and conditioned taste aversion (CTA) analysis. After tests, telemetric temperature sensors were implanted, and core-body temperature monitored.

\section{Open-field test}

The open-field (OF) test was conducted in a non-covered, white methacrylate box ( $56 \times 36.5$ $x 31 \mathrm{~cm}$ ) that allows for video recording during animal testing. Mice were individually exposed for $5 \mathrm{~min}$ to the OF before receiving rotational or control stimulation. After stimulation, mice were re-exposed to the OF for 60 more min. For optogenetic experiments, 
mice were exposed for a total of $60 \mathrm{~min}$ to the OF ( $5 \mathrm{~min}$ of pre-stimulation, followed by 5 min of laser stimulation and 50 min of post-stimulation). Spontaneous ambulatory activity was monitored using a video tracking software (Ethovision XT 11.5; Noldus Information Technology).

\section{Appetite-suppression test}

Animals were individually placed in an Oxyletpro-Physiocage monitoring system (Panlab) for real-time quantification of food and liquid intake. Mice were habituated to the cage for 2 to 4 days with ad libitum access to normal chow and water, unless otherwise stated. Prior to each session, animals were food deprived for $24 \mathrm{~h}$ and refed at the onset of the dark cycle. For specific experiments, chocolate-flavored, highly palatable liquid diet (ENSURE Nutrivigor, Abbott) was provided during cage habituation and in the subsequent experimental sessions. Food and liquid intake were expressed as cumulative intake using the Metabolism software version v3.0.00 (Panlab).

\section{Conditioned taste aversion (CTA) test}

For the CTA test, a two bottle-based protocol was used ${ }^{46}$. Animals were individually placed in a custom cage with angular ports for two liquid-containing bottles. Ad libitum water access was provided for 2 days during habituation. Next, animals only had access to both watercontaining bottles during restricted time periods (30 min access in the morning, 30-60 min in the afternoon) for 8 days (D1- D8). During days 4 and 6 (D4 and D6), a solution of 5\% sucrose in water was paired with specific stimuli (rotation, CNO injection, photostimulation) to stablish conditioning. Mice were tested on D8. Sucrose preference value was calculated as sucrose solution consumption/total liquid consumption. 


\section{Surgical implantation of telemetry devices and temperature monitoring}

Anesthetized mice ( $5 \%$ isoflurane for induction, $1.5 \%$ for maintenance) were aseptically implanted with telemetric temperature transmitters (G2 E-Mitter, STARR Life Sciences Corp.) into the peritoneum and allowed to recover for 2 weeks. Mouse cages were placed on telemetry receivers (ER4000 Energizer/Receiver, STARR Life Sciences Corp.) and core body temperature was monitored using the VitalView software version 5.0 (STARR Life Sciences Corp.) under controlled ambient temperature $\left(22^{\circ} \mathrm{C}\right)$. All recordings started in resting animals. For specific experiments, mice were inserted into a modified 50-mL Falcon tube to ensure physical restrain while allowing optogenetic tethering.

\section{Viral vector production}

pAAV-hSyn-DIO-hM4Di:mCherry, pAAV-EF1a-DIO-eYFP and pAAV-EF1a-DIO- ChR2:YFP plasmids were obtained from Addgene (\#44362, \#27056 and \#100056, respectively). pAAV RiboTag virus (pAAV-EF1a-DIO- Rpl22·HA) and pAAV-EF1a-DIOSynaptophysin:GFP (Syn.GFP) viruses have been described ${ }^{40,44}$. Recombinant adenoassociated viral vectors (AAV) were produced in human embryonic kidney (HEK293T) cells with AAV1 coat serotype. Purification was achieved by several sucrose and $\mathrm{CsCl}$ gradient centrifugations and a final re-suspension in 1x Hanks Balanced Saline Solution (HBSS) at a titer of $2 \times 10^{9}$ viral genomes/ $\mu \mathrm{L}$ as described ${ }^{40,58}$. AAV preparations were aliquoted and stored at $-80^{\circ} \mathrm{C}$ until stereotaxic injection.

\section{Stereotaxic surgery}

All surgeries were performed under aseptic conditions. Animal anesthesia was induced and maintained with $5 \%$ and $1-1.5 \%$ isoflurane $/ \mathrm{O}_{2}$, respectively. Analgesia ( $5 \mathrm{mg} / \mathrm{kg}$ ketoprofen; Sanofi-Aventis) and ocular protective gel (Viscotears ${ }^{\circledR}$, Bausch+Lomb) were applied. Mice were then placed over a heating pad in a robot-operated, 3-dimensional (stereotaxic) frame 
(Neurostar) for intracerebral virus delivery. Stereotaxic coordinates were normalized using a correction factor (Bregma-Lambda distance/4.21) based on the coordinates of Paxinos and Franklin ${ }^{59}$. AAV preparations were unilaterally (right side) or bilaterally delivered into the VN (antero-posterior (AP), $-5.65 \mathrm{~mm}$; medio-lateral (ML), $\pm 0.90 \mathrm{~mm}$; dorso-ventral (DV), -4.60 $\mathrm{mm}$ from Bregma) at a constant rate of $0.1 \mu \mathrm{L} / \mathrm{min}$ for $3.5-4.0 \mathrm{~min}(0.35-0.40 \mu \mathrm{L}$ per injection site) using a 32-guage blunt needle coupled to a $5 \mu \mathrm{L}$-syringe (Hamilton). After infusion, the needle was maintained in place for $6 \mathrm{~min}$ to allow proper diffusion. Subsequent needle withdrawal was performed at $1 \mathrm{~mm} / \mathrm{min}$ to ensure minimal off-target viral leakage.

After viral injection, mice used for optogenetic experiments also received unilateral surgical implantation of a fiber-optic cannula as described below.

\section{Chemogenetics}

Slc17a6 ${ }^{\text {Cre }}, C c k^{C r e}$ or $\mathrm{Crh}^{\text {Cre }}$ mice were bilaterally injected in the VN with $0.35 \mu \mathrm{L}$ (per side) of AAV1-hSyn-DIO-hM4Di:mCherry. Clozapine-n-oxide (CNO; $1 \mathrm{mg} / \mathrm{kg}$ ) was administered via intraperitoneal (i.p.) injection 35 min prior to rotational or control stimulation.

\section{Optogenetics}

Slc17a6 ${ }^{\text {Cre }}, C c k^{C r e}$ or $\mathrm{Crh}^{\text {Cre }}$ mice were injected in the right $\mathrm{VN}$ with $0.4 \mu \mathrm{L}$ of either AAV1EF1 $\alpha$-DIO-ChR2-YFP or AAV1-EF1 $\alpha$-DIO-eYFP and a fiber-optic cannula (200- $\mu \mathrm{m}$ fiber core diameter, 0.22-numeric aperture; 2.5-mm ferrule diameter; Thorlabs) was implanted over the right $\mathrm{VN}(\mathrm{AP},-5.65 \mathrm{~mm}$; $\mathrm{ML},+0.90 \mathrm{~mm}$; DV, $-3.80 \mathrm{~mm}$ ) or over the right PBN (AP, $-4.65 \mathrm{~mm}$; ML, $+1.70 \mathrm{~mm}$; DV, $-3.00 \mathrm{~mm}$ ) of $C c k^{C r e}$ animals. A fiber-optic cannula was fixed to the exposed skull with a layer of adhesive cement (Super-Bond C\&B, Sun Medical) and dental acrylic cement (Rebaron, GC Corporation). The skin was affixed to the cement with tissue adhesive (Vetbond, 3M). A blue 473-nm laser light was produced by a DPSS Laser System (LRS-0473-GFM-00100-05 Laserglow) and driven by a fiber-optic patch cord (200- 
$\mu \mathrm{m}$ core diameter, 0.22-numeric aperture: FT030 protection, Thorlabs). Light intensity was set at $10 \mathrm{~mW}$ measured by a photometer (Thorlabs) at the tip of a non-implanted fiber optic cannula attached to the patch-cord. To deliver illumination to the right VN or right PBN, the patch cord was connected to the implanted fiber-optic-containing cannula through a ceramic sleeve. A pulse generator (33500B Series Trueform, Keysight) was used to adjust laser output to deliver $40-\mathrm{Hz}, 10-\mathrm{ms}$, pulse trains for $5 \mathrm{~min}$ to all mice.

\section{Mapping of neuronal projections}

To visualize the presynaptic terminals of VGLUT2 ${ }^{\mathrm{VN}}$ or $\mathrm{CCK}^{\mathrm{VN}}$ neurons, Slc17a6 ${ }^{\mathrm{Cre}}$ or $\mathrm{C} c k^{\mathrm{Cre}}$ mice were injected into the right $\mathrm{VN}$ with $0.35 \mu \mathrm{L}$ of AAV1-EF1 $\alpha$-DIO-Synaptophysin:GFP ${ }^{44}$. Animals were euthanized 3 weeks after surgery for subsequent immunofluorescence analysis using an anti-GFP antibody as described below.

\section{Tissue processing and Immunofluorescence analysis}

Mouse brains were freshly dissected following euthanasia by $\mathrm{CO}_{2}$ asphyxia, fixed overnight with phosphate-buffered saline (PBS) containing 4\% paraformaldehyde (PFA) and cryoprotected with $30 \%$ sucrose in PBS. For cryo-sectioning, brains were frozen for 5 min in dry ice and sectioned in a freezing microtome. For immunofluorescence, 30- $\mu \mathrm{m}$ free-floating sections were blocked in PBS with 10\% normal donkey serum (NDS) and $0.1 \%$ Triton X-100 for $1 \mathrm{~h}$ at room temperature followed by an overnight incubation at $4^{\circ} \mathrm{C}$ with primary antibody solution containing a chicken anti-GFP (1:2000; \#ab13970, Abcam), a rabbit anti-mCherry (1:2000; \#ab167453, Abcam) or a rabbit anti-GFAP antibody (1:1000; \#PA1-10019, Invitrogen) in PBS with $1 \%$ NDS and $0.1 \%$ Triton X-100. After three washes in PBS with $0.1 \%$ Triton $\mathrm{X}-100$, a secondary antibody solution containing secondary antibodies conjugated to Alexa Fluor fluorophores (1:500; Invitrogen) was added to the sections and incubated for $1 \mathrm{~h}$ at room temperature. After the incubation, sections were washed three 
times for 5 min in PBS with $0.1 \%$ Triton X-100 and mounted onto slides with DAPI Fluoromount (\#17984-24, Electron Microscopy Sciences) before visualization with an EVOS imaging system (Thermo Fisher Sci).

\section{RiboTag assays}

For genetic identification of neuronal subsets, $S / c 17 a 6^{\text {Cre }}$ mice were bilaterally injected in the VN with $0.4 \mu \mathrm{L}$ of the RiboTag viral vector (AAV1-DIO-Rpl22HA) ${ }^{40}$. Animals were euthanized 3 weeks after surgery for subsequent RiboTag analysis. To isolate the polysome-associated mRNAs from VGLUT2 ${ }^{\mathrm{VN}}$ neurons, punches containing the VN of SIc17a6 ${ }^{\mathrm{Cre}}$ mice injected with AAV1-DIO-Rpl22·HA were pooled and homogenized in $1 \mathrm{ml}$ of buffer as described ${ }^{41}$. After centrifugation, $4 \mu \mathrm{L}$ of anti-HA antibody (MMS-101R, 2-3 mg/ml; Covance) was added to $800 \mu \mathrm{L}$ of the cleared lysate and incubated for $4 \mathrm{~h}$ at $4^{\circ} \mathrm{C}$. Remaining lysate was saved as input sample. After incubation, $200 \mu \mathrm{L}$ of protein A/G magnetic beads (Thermo Scientific) were added and incubated overnight at $4^{\circ} \mathrm{C}$ with rotation. Immunoprecipitates (IPs) were washed in high-salt buffer and RNA from inputs and IPs were extracted ${ }^{39}$. For differential expression analysis, $10 \mathrm{ng}$ of RNA was amplified using the Ovation Pico SL WTA system (NuGEN). Fidelity of amplification was confirmed by qPCR analysis of the resulting cDNA using the QuantiTect kit (Qiagen) before biotinylation according to the EncorelL biotinylation kit (NuGEN). Biotinylated cDNA was quantified, and product size distribution was analyzed using the 2100 Bioanalyzer system with the RNA 6000 Nano chips (Agilent Technologies). Biotinylated cDNA (750 ng) was hybridized at $48^{\circ} \mathrm{C}$ to MouseRef-8 v2 expression beadchips (Illumina) for $16 \mathrm{~h}$ before washing and analyzing according to the manufacturer's directions. Signal was detected using a BeadArray Reader (Illumina), and data were analyzed for differential expression using the GenomeStudio data analysis software (Illumina). Average normalization, the Illumina custom error model, and multiple testing corrections using the Benjamini-Hochberg false discovery rate were applied to the analysis. Only transcripts with a 
differential score of $>13(p<0.05)$ were considered. Normalized and raw data have been deposited in the National Center for Biotechnology Information Gene Expression Omnibus and are accessible through GEO Series accession number GSE167672 (https://www.ncbi.nlm.nih.gov/geo/query/acc.cgi?acc=GSE167672).

\section{In situ hybridization assays}

Mouse brains were fresh-frozen in Tissue-Tek O.C.T. compound (Sakura) with dry ice and stored at $-80^{\circ} \mathrm{C}$ until cryosectioning. Coronal sections $(15 \mu \mathrm{m})$ containing the VN or the PBN were used for RNAscope (Advanced Cell Diagnostics) analysis following manufacturer's directions. The following probes were used: Mm-Slc17a6 (\#319171-C3), Mm-Cck (\#402271C2), Mm-Crh (\#316091), Mm-Fos (\#316921) and Mm-Calca (\#578771-C2). All in situ hybridization assays were imaged using a confocal (Leica SP5) or epifluorescence (Nikon Eclipse 90i) microscope and analyzed in ImageJ (Fiji v1.0)

\section{Statistics}

Data are shown as the mean \pm SEM. GraphPad Prism v9.0 software was used for statistical analyses. Appropriate tests were selected depending on the experimental design as stated in the figure legends. Statistical significance, when reached $(p<0.05$ was considered significant), is stated in the figure legends.

\section{ACKNOWLEDGMENTS}

Authors thank Diane Durnam for editing the manuscript. This work was supported by a NENS exchange grant for training stay (PMM), a Marie Sklodowska-Curie Individual Fellowship (H2020-MSCA-IF-2014-658352; ES), pre-doctoral fellowships (2018FI_B 00452 
to AU; PRE2018-083179 to LSB) and two Ramón y Cajal fellowships (RyC-2012-11873;

AQ, RYC2019-028501-I; ES). E.S received funds from MICIU Proyectos I+D+i "Retos

Investigacion" (RTI2018-101838-J-I00). A.Q. received funds from the European Research

Council (Starting grant NEUROMITO, ERC-2014-StG-638106), MINECO Proyectos I+D de

Excelencia (SAF2014-57981P; SAF2017-88108-R), MICINN Proyectos I+D+i (PID2020-

114977RB-I00), AGAUR (2017SGR-323) and "la Caixa" Foundation (ID 100010434), under the agreement LCF/PR/HR20/52400018.

\section{AUTHOR CONTRIBUTIONS}

RP, ES and AQ conceived, designed, and supervised the work. PMM, LSB, FM, AU, IA, ES and $A Q$ acquired, analyzed, and interpreted the data. The manuscript was written by PMM, $R P, E S$ and $A Q$ and revised and edited by all authors.

\section{COMPETING INTERESTS STATEMENT}

The authors declare no competing interests.

\section{REFERENCES}

1. Bertolini, G. \& Straumann, D. Moving in a Moving World: A Review on Vestibular Motion Sickness. Frontiers in neurology 7, 14-14 (2016).

2. Graybiel, A., Wood, C.D., Miller, E.F. \& Cramer, D.B. Diagnostic criteria for grading the severity of acute motion sickness. Aerospace medicine 39, 453-455 (1968).

3. Money, K.E. Motion sickness. Physiological Reviews 50, 1-39 (1970).

4. Nalivaiko, E. Thermoregulation and nausea. 445-456 (2018). 
5. Previc, F.H. Do the organs of the labyrinth differentially influence the sympathetic and parasympathetic systems? Neuroscience and biobehavioral reviews 17, 397-404 (1993).

6. $\quad$ Treisman, M. Motion sickness: an evolutionary hypothesis. Science 197, 493-495 (1977).

7. Helling, K., Hausmann, S., Clarke, A. \& Scherer, H. Experimentally induced motion sickness in fish: possible role of the otolith organs. Acta oto-laryngologica 123, 488492 (2003).

8. Ngampramuan, S., et al. Thermoregulatory correlates of nausea in rats and musk shrews. Oncotarget 5, 1565-1575 (2014).

9. Wei, X., et al. Verification of motion sickness index in mice. CNS neuroscience \& therapeutics 17, 790-792 (2011).

10. Lackner, J.R. Motion sickness: more than nausea and vomiting. Exp Brain Res 232, 2493-2510 (2014).

11. Bles, W., Bos, J.E., de Graaf, B., Groen, E. \& Wertheim, A.H. Motion sickness: only one provocative conflict? Brain Res Bull 47, 481-487 (1998).

12. Reason, J.T. Motion Sickness Adaptation: A Neural Mismatch Model. Journal of the Royal Society of Medicine 71, 819-829 (1978).

13. Oman, C.M. Sensory conflict in motion sickness: an Observer Theory approach. Pictorial communication in virtual and real environments, 362-376 (1991).

14. James, W. THE SENSE OF DIZZINESS IN DEAF-MUTES. American Annals of the Deaf and Dumb 28, 102-117 (1883).

15. Irwin, J.A. The pathology of sea-sickness. The Lancet 118, 907-909 (1881).

16. Abe, C., Tanaka, K., Iwata, C. \& Morita, H. Vestibular-mediated increase in central serotonin plays an important role in hypergravity-induced hypophagia in rats. Journal of Applied Physiology 109, 1635-1643 (2010).

17. Murakami, D.M., Erkman, L., Hermanson, O., Rosenfeld, M.G. \& Fuller, C.A. Evidence for vestibular regulation of autonomic functions in a mouse genetic model. Proceedings of the National Academy of Sciences 99, 17078-17082 (2002).

18. Dieterich, M., et al. Medial Vestibular Nucleus Lesions in Wallenberg's Syndrome Cause Decreased Activity of the Contralateral Vestibular Cortex. Annals of the New York Academy of Sciences 1039, 368-383 (2005).

19. Angelaki, D.E. \& Cullen, K.E. Vestibular system: the many facets of a multimodal sense. Annu Rev Neurosci 31, 125-150 (2008).

20. Yates, B.J., Holmes, M.J. \& Jian, B.J. Adaptive plasticity in vestibular influences on cardiovascular control. Brain research bulletin 53, 3-9 (2000).

21. Yates, B.J. \& Miller, A.D. Properties of sympathetic reflexes elicited by natural vestibular stimulation: implications for cardiovascular control. Journal of Neurophysiology 71, 2087-2092 (1994).

22. Braun, J.J. \& McIntosh, H. Learned taste aversions induced by rotational stimulation. Physiological Psychology 1, 301-304 (1973).

23. Fuller, P.M., Jones, T.A., Jones, S.M. \& Fuller, C.A. Neurovestibular modulation of circadian and homeostatic regulation: vestibulohypothalamic connection? Proceedings of the National Academy of Sciences of the United States of America 99, 15723-15728 (2002).

24. Nalivaiko, E., Rudd, J.A. \& So, R.H.Y. Motion sickness, nausea and thermoregulation: The "toxic" hypothesis. Temperature: Multidisciplinary Biomedical Journal 1, 164-164 (2014).

25. Palmiter, R.D. The Parabrachial Nucleus: CGRP Neurons Function as a General Alarm. Trends in neurosciences 41, 280-293 (2018).

26. Balaban, C.D. Vestibular nucleus projections to the parabrachial nucleus in rabbits: implications for vestibular influences on the autonomic nervous system. Exp Brain Res 
108, 367-381 (1996).

27. Balaban, C.D. \& Beryozkin, G. Vestibular nucleus projections to nucleus tractus solitarius and the dorsal motor nucleus of the vagus nerve: potential substrates for vestibulo-autonomic interactions. Experimental brain research 98, 200-212 (1994).

28. Erö, C., Gewaltig, M.-O., Keller, D. \& Markram, H. A Cell Atlas for the Mouse Brain. Frontiers in Neuroinformatics 12, 84-84 (2018).

29. Abe, C., et al. VGLUT2-expressing neurons in the vestibular nuclear complex mediate gravitational stress-induced hypothermia in mice. Commun Biol 3, 227 (2020).

30. Holstein, G.R., Friedrich, V.L., Jr. \& Martinelli, G.P. Glutamate and GABA in VestibuloSympathetic Pathway Neurons. Front Neuroanat 10, 7 (2016).

31. Gagliuso, A.H., Chapman, E.K., Martinelli, G.P. \& Holstein, G.R. Vestibular neurons with direct projections to the solitary nucleus in the rat. $J$ Neurophysiol 122, 512-524 (2019).

32. Cai, Y.-L., et al. Glutamatergic vestibular neurons express Fos after vestibular stimulation and project to the NTS and the PBN in rats. Neuroscience Letters 417, 132 137 (2007).

33. Singh, P., Yoon, S.S. \& Kuo, B. Nausea: a review of pathophysiology and therapeutics. Therap Adv Gastroenterol 9, 98-112 (2016).

34. $\mathrm{Ng}, \mathrm{L}$., et al. An anatomic gene expression atlas of the adult mouse brain. Nature Neuroscience 12, 356-362 (2009).

35. Borgius, L., Restrepo, C.E., Leao, R.N., Saleh, N. \& Kiehn, O. A transgenic mouse line for molecular genetic analysis of excitatory glutamatergic neurons. Molecular and cellular neurosciences 45, 245-257 (2010).

36. Lidvall, H.F. Mechanisms of motion sickness as reflected in the vertigo and nystagmus responses to repeated caloric stimuli. Acta Otolaryngol 55, 527-536 (1962).

37. Bolea, I., et al. Defined neuronal populations drive fatal phenotype in a mouse model of Leigh syndrome. Elife 8 (2019).

38. Waespe, W. \& Henn, V. The velocity response of vestibular nucleus neurons during vestibular, visual, and combined angular acceleration. Exp Brain Res 37, 337-347 (1979).

39. Sanz, E., Bean, J.C., Carey, D.P., Quintana, A. \& McKnight, G.S. RiboTag: Ribosomal Tagging Strategy to Analyze Cell-Type-Specific mRNA Expression In Vivo. Curr Protoc Neurosci 88, e77 (2019).

40. Sanz, E., et al. Fertility-regulating Kiss1 neurons arise from hypothalamic POMCexpressing progenitors. J Neurosci 35, 5549-5556 (2015).

41. Sanz, E., et al. Cell-type-specific isolation of ribosome-associated mRNA from complex tissues. Proc Natl Acad Sci U S A 106, 13939-13944 (2009).

42. Parrott, R.F., Ebenezer, I.S., Baldwin, B.A. \& Forsling, M.L. Central and peripheral doses of cholecystokinin that inhibit feeding in pigs also stimulate vasopressin and cortisol release. Exp Physiol 76, 525-531 (1991).

43. Nijsen, M.J., et al. The role of the CRH type 1 receptor in autonomic responses to corticotropin- releasing hormone in the rat. Neuropsychopharmacology 22, 388-399 (2000).

44. Carter, M.E., Soden, M.E., Zweifel, L.S. \& Palmiter, R.D. Genetic identification of a neural circuit that suppresses appetite. Nature 503, 111-114 (2013).

45. Gallo, M., Marquez, S.L., Ballesteros, M.A. \& Maldonado, A. Functional blockade of the parabrachial area by tetrodotoxin disrupts the acquisition of conditioned taste aversion induced by motion-sickness in rats. Neuroscience letters 265, 57-60 (1999).

46. Chen, J.Y., Campos, C.A., Jarvie, B.C. \& Palmiter, R.D. Parabrachial CGRP Neurons Establish and Sustain Aversive Taste Memories. Neuron 100, 891-899 e895 (2018).

47. Campos, C.A., et al. Cancer-induced anorexia and malaise are mediated by CGRP neurons in the parabrachial nucleus. Nat Neurosci 20, 934-942 (2017). 
48. Carter, M.E., Han, S. \& Palmiter, R.D. Parabrachial calcitonin gene-related peptide neurons mediate conditioned taste aversion. J Neurosci 35, 4582-4586 (2015).

49. Bernstein, I.L. Learned taste aversions in children receiving chemotherapy. Science 200, 1302-1303 (1978).

50. Previc, F.H. Intravestibular Balance and Motion Sickness. Aerosp Med Hum Perform 89, 130-140 (2018).

51. Kodama, T., et al. Neuronal classification and marker gene identification via single-cell expression profiling of brainstem vestibular neurons subserving cerebellar learning. $J$ Neurosci 32, 7819-7831 (2012).

52. Lin, Y. \& Carpenter, D.O. Medial vestibular neurons are endogenous pacemakers whose discharge is modulated by neurotransmitters. Cellular and Molecular Neurobiology 13, 601-613 (1993).

53. Ris, L., Capron, B., Vibert, N., Vidal, P.P. \& Godaux, E. Modification of the pacemaker activity of vestibular neurons in brainstem slices during vestibular compensation in the guinea pig. Eur J Neurosci 13, 2234-2240 (2001).

54. Norris, A.J., Shaker, J.R., Cone, A.L., Ndiokho, I.B. \& Bruchas, M.R. Parabrachial opioidergic projections to preoptic hypothalamus mediate behavioral and physiological thermal defenses. Elife 10 (2021).

55. Tan, C.L., et al. Warm-Sensitive Neurons that Control Body Temperature. Cell 167, 47-59 e15 (2016).

56. Roman, C.W., Derkach, V.A. \& Palmiter, R.D. Genetically and functionally defined NTS to PBN brain circuits mediating anorexia. Nat Commun 7, 11905 (2016).

57. Taniguchi, $\mathrm{H}$., et al. A resource of Cre driver lines for genetic targeting of GABAergic neurons in cerebral cortex. Neuron 71, 995-1013 (2011).

58. Quintana, A., et al. Fatal breathing dysfunction in a mouse model of Leigh syndrome. J Clin Invest 122, 2359-2368 (2012).

59. Franklin, K.B.J. \& Paxinos, G. Paxinos and Franklin's The mouse brain in stereotaxic coordinates (Academic Press, an imprint of Elsevier, Amsterdam, 2013).

\section{FIGURES}

\section{Fig. 1: VGLUT2 ${ }^{\mathrm{VN}}$ neuron inactivation blocks rotation-induced kinetosis in mice. a,}

Mice were subjected to a rotational stimulus using a custom-made rotary device.

Perpendicular distance from the mouse head to the axis of rotation was $5 \mathrm{~cm}$. Mouse body inclination angle was $45^{\circ}$. b. Traveled distance during $60 \mathrm{~min}$ of open-field test after spin or control stimulation ( $\mathrm{n}=6$; Two-way ANOVA, $P<0.001$ ). $\mathbf{c}$, Cumulative food intake after spin or control stimulation ( $\mathrm{n}=6$; Two-way ANOVA, $P<0.01$ ). Mice were food deprived for $24 \mathrm{~h}$ prior to the test. d, Body temperature difference $(\Delta T)$ after spin or control stimulation $(n=5$; Two-way ANOVA, $P<0.01)$. e, S/c17a6 ${ }^{\text {Cre }}$ mice were bilaterally injected in the vestibular 
nuclei (VN) with AAV1-DIO-hM4Di·mCherry (Vglut2 ${ }^{\mathrm{VN}}: \mathrm{hM} 4 \mathrm{Di}$ mice) to inhibit glutamatergic neurons upon CNO administration. f, Total distance traveled during a 60-min open-field session after spin stimulation in CNO- or vehicle-injected Vglut2 ${ }^{\mathrm{VN}}$ :hM4Di mice ( $\mathrm{h}=10$; Twoway ANOVA, $P<0.01)$. g, Cumulative food intake after spin stimulation in CNO- or vehicleinjected Vglut2 ${ }^{\mathrm{VN}}$ :hM4Di mice ( $\mathrm{n}=7$; Two-way ANOVA, $\left.P<0.001\right)$. Mice were food deprived for $24 \mathrm{~h}$ prior to the test. $\mathbf{h}$, Body temperature difference $(\Delta \mathrm{T})$ after spin stimulation in CNOor vehicle-injected Vglut2 ${ }^{\mathrm{VN}}$ :hM4Di mice ( $\mathrm{n}=4$; Two-way ANOVA, $\left.P<0.05\right)$. Arrow shows time of injection.

Fig. 2: VGLUT2 ${ }^{\mathrm{VN}}$ neuron activation is sufficient to induce kinetosis. a, S/c17a6 $6^{\mathrm{Cre}}$ mice were unilaterally injected in the right $\mathrm{VN}$ with $\mathrm{AAV1}$-DIO-ChR2·YFP (Vglut2 ${ }^{\mathrm{VN}}: \mathrm{ChR} 2$ mice) or AAV1-DIO-YFP (Vglut2 ${ }^{\mathrm{VN}}$ :YFP mice), followed by optical fiber implantation over the right VN to deliver $40-\mathrm{Hz}, 10-\mathrm{ms}, 10-\mathrm{mW}, 473-\mathrm{nm}$ light pulses for $5 \mathrm{~min}$ under different behavioral approaches. b, Traveled distance during 60 min of open-field test after photostimulation (Vglut2 ${ }^{\mathrm{VN}}:$ ChR2 mice $\mathrm{n}=7$; Vglut2 ${ }^{\mathrm{VN}}$ :YFP mice $\mathrm{n}=5$; two-way ANOVA, $P<0.01)$. c, Normal-chow intake following laser onset in $\mathrm{Vglut}^{\mathrm{VN}}: \mathrm{ChR} 2$ or $\mathrm{Vglut}^{\mathrm{VN}}$ :YFP mice. Animals were food-deprived for $24 \mathrm{~h}$ prior to photostimulation. ( $\mathrm{n}=6$; Two-way ANOVA, $P<0.001)$. d, Water intake following laser onset in food-deprived, Vglut2 ${ }^{\mathrm{VN}}: \mathrm{ChR} 2$ or Vglut2 ${ }^{\mathrm{VN}}$ :YFP mice $(\mathrm{n}=6$; Two-way ANOVA, $\mathrm{P}<0.001)$. e, Highly palatable, chocolateflavored drink intake following laser onset in food-deprived $\mathrm{Vglut}^{\mathrm{VN}}$ :ChR2 or Vglut2 ${ }^{\mathrm{VN}}$ :YFP animals ( $n=6$; Two-way ANOVA, $P>0.05$ ).

f, Core body temperature difference $(\Delta \mathrm{T})$ in freely moving Vglut2 ${ }^{\mathrm{VN}}: \mathrm{ChR2}$ or Vglut2 ${ }^{\mathrm{VN}}: \mathrm{YFP}$ mice after handling and laser stimulation ( $n=8$; Two-way ANOVA, $P<0.01)$. g, Core body temperature difference $(\Delta \mathrm{T})$ after photostimulation in restrained Vglut2 ${ }^{\mathrm{VN}}$.ChR2 or Vglut2 $^{\mathrm{VN}}$ :YFP mice ( $\mathrm{n}=5$; Two-way ANOVA, $\left.P<0.001\right)$. YFP: Vglut2 ${ }^{\mathrm{VN}}$ :YFP mice; ChR2: Vglut2 ${ }^{\mathrm{VN}}:$ ChR2 mice. 
Fig. 3: Identification of VN glutamatergic subpopulations and their role in kinetosis.

a, S/c17a6 $6^{\text {Cre }}$ mice $(n=3)$ were bilaterally injected in the $\mathrm{VN}$ with a viral vector expressing the RiboTag (AAV1-DIO-Rpl22HA) for the molecular profiling of VGLUT2 ${ }^{\mathrm{VN}}$ neurons. $\mathbf{b}$, Differential expression analysis showing significant enrichment for candidate VGLUT2 ${ }^{\mathrm{VN}}$ neuron subpopulation marker transcripts in the immunoprecipitates of RiboTag assays when compared to inputs. Specific enrichment for S/c17a6 (Vglut2), and depletion for inhibitory neuron (Gad2) and non-neuronal marker transcripts (Cnp, Gfap) were confirmed in the analysis (padj: adjusted $P$-value; FC: fold change). c, Double-label in situ hybridization assay (RNAscope) showing expression of Crh mRNA within Slc17a6expressing cells. Scale bar: $100 \mu \mathrm{m}$. d, $\mathrm{Crh}^{\mathrm{Cre}}$ mice were bilaterally injected in the VN with AAV1-DIO- hM4Di-mCherry (Crh ${ }^{\mathrm{VN}}: \mathrm{hM} 4 \mathrm{Di}$ mice) to inhibit $\mathrm{CRH}^{\mathrm{VN}}$ neurons upon CNO administration. e, Locomotor activity in Crh ${ }^{\mathrm{VN}}$ :hM4Di mice after spin stimulation in CNO and vehicle-injected mice ( $n=9$; Two-way ANOVA, $P>0.05)$. f, Body core temperature difference $(\Delta \mathrm{T})$ in $\mathrm{CNO}$ or vehicle-injected $\mathrm{Crh}^{\mathrm{VN}}$ :hM4Di mice after spin stimulation ( $\mathrm{n}=4$; Two-way ANOVA, $P>0.05$ ). Arrow shows time of injection. $\mathbf{g}$, Double-label in situ hybridization assay (RNAscope) showing expression of Cck mRNA within Slc17a6-expressing cells. Scale bar: $100 \mu \mathrm{m} . \mathbf{h}, \mathrm{Cck}^{\text {Cre }}$ mice were bilaterally injected in the VN with AAV1-DIO- hM4Di-mCherry (Cck ${ }^{\mathrm{VN}}$ :hM4Di mice) to inhibit $\mathrm{CCK}^{\mathrm{VN}}$ neurons upon $\mathrm{CNO}$ administration. i, 5-min open-field test in $\mathrm{Cck}^{\mathrm{VN}}$ :hM4Di mice 30 minutes after $\mathrm{CNO}$ or vehicle administration $(\mathrm{n}=4$; $\mathrm{t}$-test, $P<0.01)$. j, Open-field test in $\mathrm{Cck}^{\mathrm{VN}}$ :hM4Di mice injected with $\mathrm{CNO}$ or vehicle after spin stimulation ( $n=4$; Two-way ANOVA, $P<0.001)$. $\mathbf{k}$, Body core temperature difference $(\Delta T)$ in Cck $^{\mathrm{VN}}$ :hM4Di mice after CNO or vehicle administration ( $\mathrm{n}=4$; Two-way ANOVA, $\left.P<0.001\right)$. Arrow shows time of injection. I, Body core temperature difference $(\Delta T)$ in $\mathrm{CNO}$ or vehicleinjected $\mathrm{Cck}^{\mathrm{VN}}$ :hM4Di mice after spin stimulation ( $\mathrm{n}=4$; two-way ANOVA, P-value<0.001). Arrow shows time of injection. 
Fig. 4: Photoactivation of $\mathrm{CCK}^{\mathrm{VN}}$ neurons induces kinetosis. a, $C c k^{\mathrm{Cre}}$ mice were unilaterally injected in the right VN with AAV1-DIO-ChR2·YFP (Cck ${ }^{\mathrm{VN}}: \mathrm{ChR} 2$ mice) or AAV1DIO-YFP (Cck ${ }^{\mathrm{VN}}$ :YFP mice) followed by an optical fiber implantation to deliver a 5-min, 473nm laser stimulation (40-Hz, 10-mW, 10-ms pulses). b, Representative image at Bregma $6.0 \mathrm{~mm}$ showing ChR2.YFP and GFAP staining in a section containing the VN of $\mathrm{Cck}^{\mathrm{VN}}$ :ChR2-YFP mice. GFAP staining revealed the optical fiber tract over the VN. c, Openfield test showing traveled distance after photostimulation in $\mathrm{Cck}^{\mathrm{VN}}: \mathrm{ChR2}$ and $\mathrm{Cck}^{\mathrm{VN}}$ :YFP mice ( $n=4$; Two-way ANOVA, $P<0.01)$. d, Normal-chow intake after light stimulation in $\mathrm{Cck}^{\mathrm{VN}}: \mathrm{ChR} 2$ and $\mathrm{Cck}^{\mathrm{VN}}$ :YFP mice. Mice were food deprived for $24 \mathrm{~h}$ prior to stimulation $(n=4$; Two-way ANOVA, $P<0.05)$. e, Body core temperature difference $(\Delta \mathrm{T})$ in $\mathrm{Cck}^{\mathrm{VN}}$ :ChR2 and Cck ${ }^{\mathrm{VN}}$ :YFP mice after handling and laser stimulation ( $\mathrm{n}=4$; Two-way ANOVA, $\left.P<0.01\right)$.

Fig. 5: VGLUT2 ${ }^{\mathrm{VN}}$ and $C \mathrm{CK}^{\mathrm{VN}}$ neurons target the PBN. a, Illustration showing AAV1-DIOSyn.GFP VN injection in S/c17a6 ${ }^{\mathrm{Cre}}$ mice for projection analysis of VGLUT2 ${ }^{\mathrm{VN}}$ neurons in the PBN. b, Representative image of Syn GFP staining in the PBN of S/c17a6 ${ }^{\text {Cre }}$ animals injected with AAV1-DIO-Syn.GFP in the VN. Scale bar: $800 \mu \mathrm{m}$. c, Schematic of AAV1DIO-Syn.GFP injection in the $\mathrm{VN}$ of $C \mathrm{Ck}^{\mathrm{Cre}}$ mice for projection analysis of $\mathrm{CCK}^{\mathrm{VN}}$ neurons in the PBN. d, Representative image of Syn.GFP staining in the PBN of $C c k^{C r e}$ animals injected with AAV1-DIO-Syn.GFP in the VN. Scale bar: $800 \mu \mathrm{m}$. Panels b and d are from Bregma $-5.2 \mathrm{~mm}$ to Bregma $-5.34 \mathrm{~mm}$. e, Illustration showing AAV1-DIO-ChR2·YFP or AAV1-DIO-YFP injection in the VN and optical fiber implantation over the PBN in $\mathrm{Cck}^{\mathrm{Cre}}$ mice for photoactivation of $\mathrm{CCK}^{\mathrm{VN}}$ neuron projections in the $\mathrm{PBN}\left(\mathrm{CCK}^{\mathrm{VN} \rightarrow P B N}\right)$. $\mathbf{f}$, Open-field test showing traveled distance after $\mathrm{CCK}^{\mathrm{VN} \rightarrow P B N}$ photostimulation $(n=4$; Two-way ANOVA, $P>0.05)$. g, Food intake in food-deprived mice after $\mathrm{CCK}^{\mathrm{VN} \rightarrow P B N}$ photostimulation $(n=3$; twoway ANOVA, P-value>0.05). h, Core body temperature difference $(\Delta T)$ after handling and 
$\mathrm{CCK}^{\mathrm{VN} \rightarrow \mathrm{PBN}}$ optogenetic stimulation $\left(\mathrm{Cck}^{\mathrm{VN} \rightarrow P B N}: \mathrm{ChR2}\right.$ mice $\mathrm{n}=3$; $\mathrm{Cck}^{\mathrm{VN} \rightarrow \mathrm{PBN}}: \mathrm{YFP}$ mice $\mathrm{n}=4$; Two-way ANOVA, $P>0.05)$.

Fig. 6: $\mathrm{CCK}^{\mathrm{VN}}$ neuron projections to the PBN mediate conditioned taste aversion (CTA). a, Illustration depicting the cage used in the two-bottle CTA test. b-f, CTA response in mice exposed to a two-bottle-based test pairing a $5 \%$ sucrose solution to different stimuli including rotational stimulus $(\mathbf{b})(n=4$; t-test, $P$-value $<0.001)$, optogenetic activation of $\mathrm{CCK}^{\mathrm{VN}}$ neurons in $\mathrm{Cck}^{\mathrm{VN}}: \mathrm{ChR2} \cdot \mathrm{YFP}$ or control $\left(\mathrm{Cck}^{\mathrm{VN}}\right.$ :YFP) mice $(\mathrm{c})(\mathrm{n}=4$; t-test, $P<0.01)$,

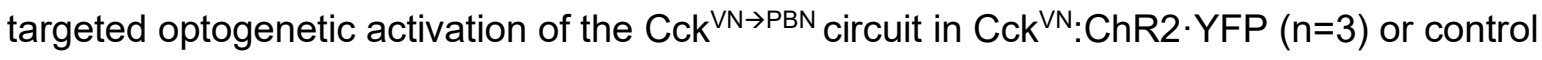
$\left(\mathrm{Cck}^{\mathrm{VN}}:\right.$ YFP; $\left.\mathrm{n}=4\right)$ mice $(\mathrm{d})(\mathrm{t}-\mathrm{test}, P<0.05)$, rotational stimulus in Vglut2 ${ }^{\mathrm{VN}}: \mathrm{hM} 4 \mathrm{Di}$ mice injected with CNO $(n=4)$ or vehicle $(n=3)(e)(t-t e s t, P<0.001)$, or optogenetic activation of VGLUT2 $^{\mathrm{VN}}$ neurons in Vglut2 ${ }^{\mathrm{VN}}: \operatorname{ChR} 2 \cdot \mathrm{YFP}(\mathrm{n}=8)$ or control Vglut2 ${ }^{\mathrm{VN}}$ :YFP $(\mathrm{n}=6)$ mice $(\mathbf{f})(\mathrm{t}-$ test, $P>0.05$ ). g, Double-label in situ hybridization assay (RNAscope) at Bregma $-5.2 \mathrm{~mm}$ showing expression of Fos mRNA within Calca-expressing neurons in the PBN of photostimulated Cck ${ }^{\mathrm{VN}}:$ ChR2·YFP mice. Control mice were Cck ${ }^{\mathrm{VN}}$ :YFP. Scale bar: $250 \mu \mathrm{m}$.

\section{Fig. 7: A genetically defined model for vestibular-mediated neurobiological MS}

regulation. Inner ear stimuli, such as exposure to rotations, leads to the activation of VGLUT2 ${ }^{\mathrm{VN}}$ neuronal subpopulations, mostly $\mathrm{CCK}^{\mathrm{VN}}$, leading to hypolocomotion,

hypophagia, hypothermia and CTA development. Our results show that hypothermia and CTA are mediated by $\mathrm{CCK}^{\mathrm{VN} \rightarrow \mathrm{PBN}}$ projections onto $\mathrm{CGRP}^{\mathrm{PBN}}$ neurons, while hypolocomotion and hypophagia are driven by different (yet to be identified) $\mathrm{CCK}^{\mathrm{VN}}$ projections. We propose that $\mathrm{CRH}^{\mathrm{VN}}$ neurons impinge onto $\mathrm{CCK}^{\mathrm{VN}}$ neurons, while other $\mathrm{VGLUT2}{ }^{\mathrm{VN}}$ subpopulations provide opposing effects, likely by activating local inhibitory neurons (gray neurons).

\section{Extended Data Fig. 1: Effect of increasing rotational intensities and VGLUT2 ${ }^{\text {VN }}$}


neuron chemogenetic inhibition on ambulatory activity in mice. a, Open field (OF) test showing reduced locomotor activity in mice subjected to rotational stimuli of different intensity and duration. Centrifugation at 234, 270 and $468 \mathrm{rpm}$ produce a centrifugal force of 3, $4(n=6)$ and $12 g(n=2)$, respectively ( $n=6$; Two-way ANOVA, $P<0.001)$. b, Representative image at Bregma $-6.0 \mathrm{~mm}$ showing $\mathrm{hM} 4 \mathrm{Di} \cdot \mathrm{mCherry}$ expression in the $\mathrm{VN}$ of Vglut2 $^{\mathrm{VN}}$ :hM4Di mice. Scale bar: $800 \mu \mathrm{m}$. c, Spontaneous ambulatory activity of Vglut2 $^{\mathrm{VN}}$ :hM4Di mice 30 min after CNO or vehicle administration in a 5-min, open-field test $(\mathrm{n}=10 ; \mathrm{t}$-test, $P>0.05)$.

\section{Extended Data Fig. 2: Increasing photostimulation frequencies decrease ambulatory} activity in mice. a, Representative image at Bregma $-6.0 \mathrm{~mm}$ showing ChR2·YFP and GFAP staining in a section containing the $\mathrm{VN}$ of $\mathrm{Vglut} 2^{\mathrm{VN}}: \mathrm{ChR} 2 \cdot \mathrm{YFP}$ mice. GFAP staining reveals the optical fiber tract over the VN. Scale bar: $800 \mu \mathrm{m}$. b, Open field test showing traveled distance elicited by different unilateral photostimulation frequencies in Vglut2 $^{\mathrm{VN}}:$ YFP and Vglut2 ${ }^{\mathrm{VN}}: \mathrm{ChR2} \cdot \mathrm{YFP}^{\mathrm{mice}}$

\section{Extended Data Fig. 3: $C R H^{\mathrm{VN}}$ neuron chemogenetic inhibition does not alter} ambulatory activity, but photoactivation of $\mathrm{CRH}^{\mathrm{VN}}$ neurons reduces ambulatory activity and decreases core body temperature. a, Locomotor activity in Crh ${ }^{\mathrm{VN}}: \mathrm{hM} 4 \mathrm{Di}$ mice (in a 5-min, open-field session) $30 \mathrm{~min}$ after CNO or vehicle administration; ( $\mathrm{n=9}$; ttest, $\mathrm{P}>0.05)$. $\mathbf{b}$, Crh-cre mice were unilaterally injected in the right $\mathrm{VN}$ with AAV1-DIOChR2·YFP (Crh ${ }^{\mathrm{VN}}:$ ChR2 mice) or AAV1-DIO-YFP (Crh ${ }^{\mathrm{VN}}$ :YFP mice) followed by an optical fiber implantation to deliver a 5-min, 473-nm laser stimulation $(40-\mathrm{Hz}, 10-\mathrm{mW}, 10-\mathrm{ms}$ pulses). c, Open-field test showing traveled distance after a 5-min photostimulation $(40-\mathrm{Hz}$, 10-mW, 10-ms pulses) over the VN of Crh ${ }^{\mathrm{VN}}: \mathrm{ChR} 2$ mice $(\mathrm{n}=6)$ or $\mathrm{Crh}^{\mathrm{VN}}$ :YFP mice $(n=4)$. Two-way ANOVA, $P<0.01$. d, Body core temperature change in $\mathrm{Crh}^{\mathrm{VN}}: \mathrm{ChR} 2(\mathrm{n}=6)$ and 
Crh ${ }^{\mathrm{VN}}$ :YFP $(\mathrm{n}=4)$ mice after handling and laser stimulation (Two-way ANOVA, $\left.\mathrm{P}<0.001\right)$.

\section{Extended Data Fig. 4: ChR2-YFP projections to the PBN and NTS in Cck ${ }^{\mathrm{VN}}:$ ChR2 $\cdot$ YFP}

mice. a-b, Representative images showing ChR2·YFP and GFAP staining in sections

containing the PBN (a; at Bregma $-5.2 \mathrm{~mm}$ ) or the NTS (b; at Bregma $-7.56 \mathrm{~mm}$ ) of

$\mathrm{Cck}^{\mathrm{VN}}:$ ChR2 mice. GFAP staining evidence the optical fiber tract over the PBN in (a). DAPI is used as a nuclear counterstain. Scale bar: $800 \mu \mathrm{m}$ (a); $400 \mu \mathrm{m}$ (b).

\section{Extended Data Fig. 5: Fos induction in CGRP PBN neurons after spin.}

Double-label in situ hybridization assay (RNAscope) at Bregma -5.2 mm showing expression of Fos mRNA within Calca-expressing neurons in the PBN after rotational stimulation. Scale bar: $250 \mu \mathrm{m}$. 
Fig. 1

a

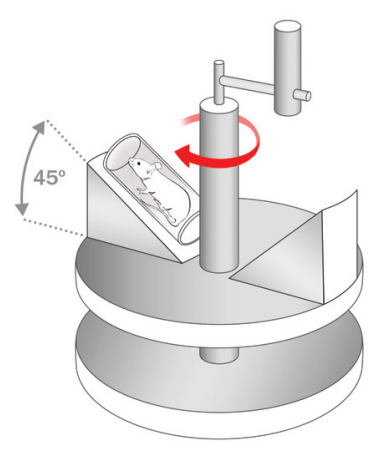

C

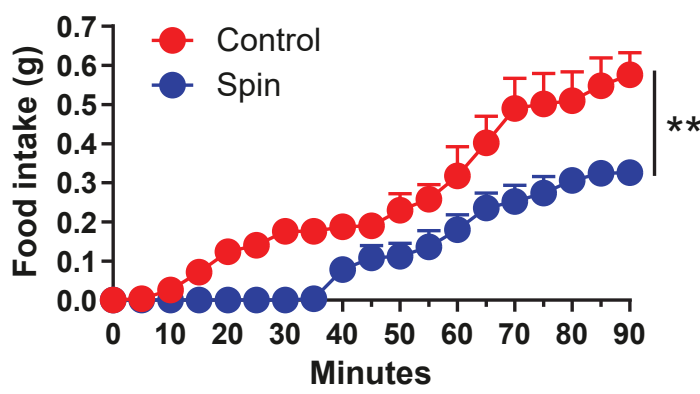

e

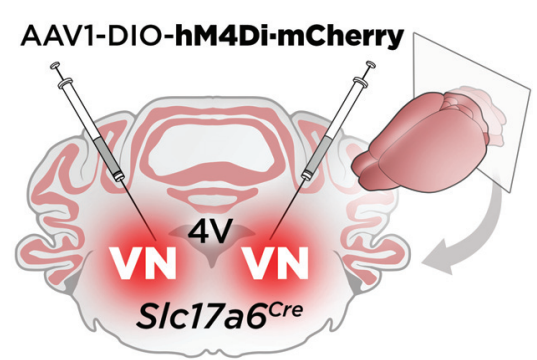

g

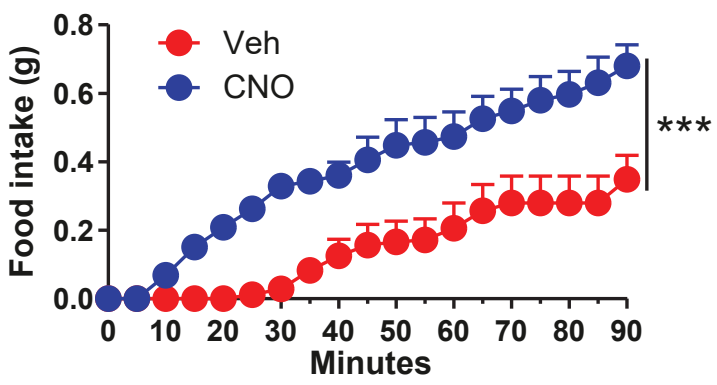

b

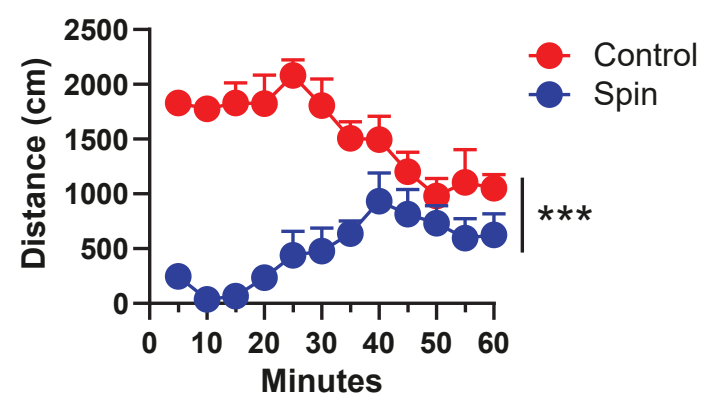

d

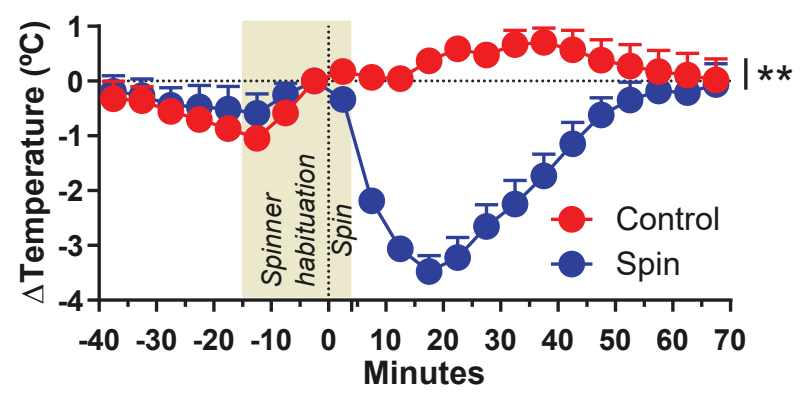

f

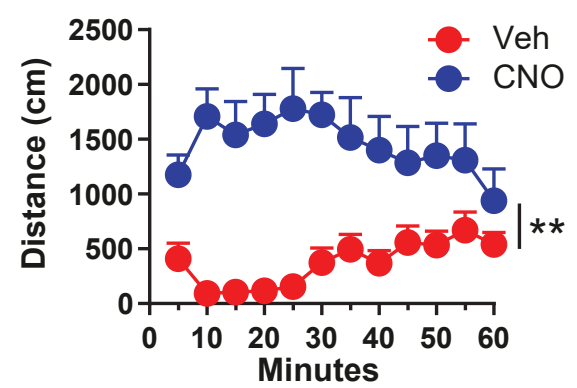

h

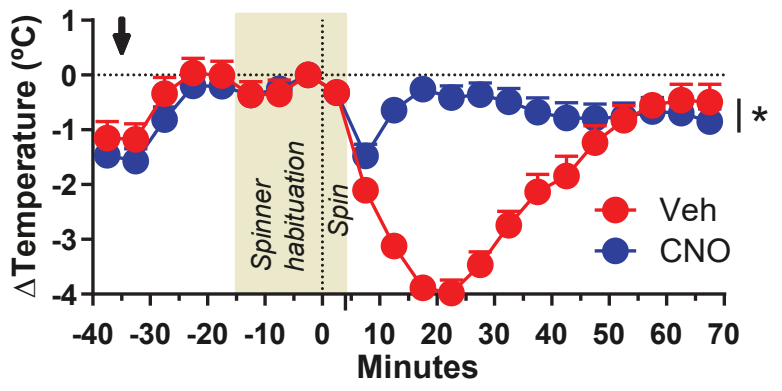


Fig. 2

a

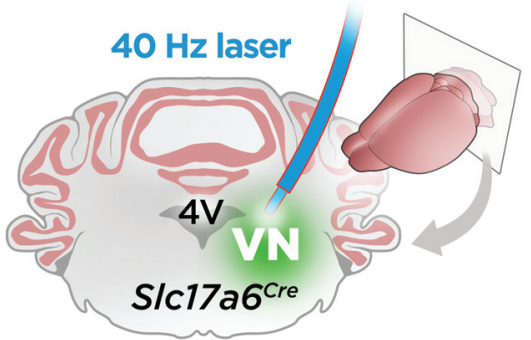

b

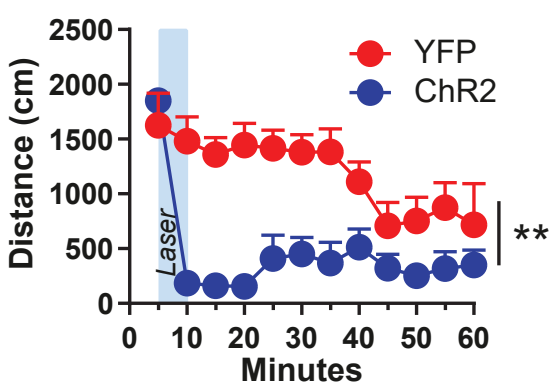

d

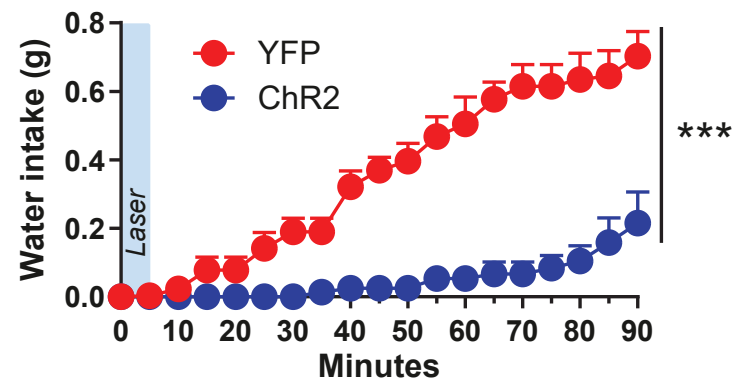

f

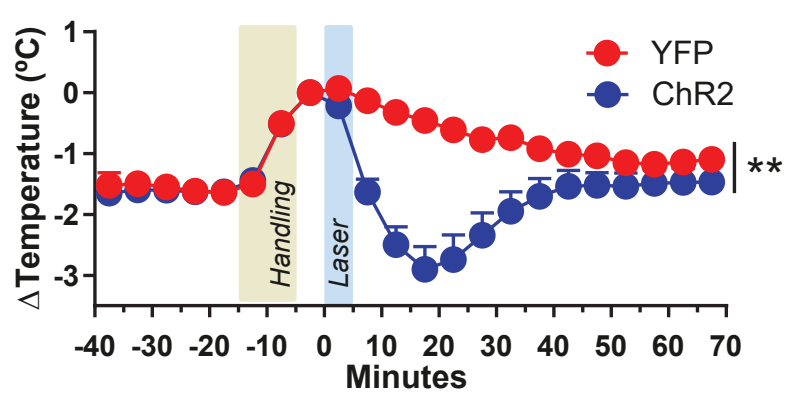

C

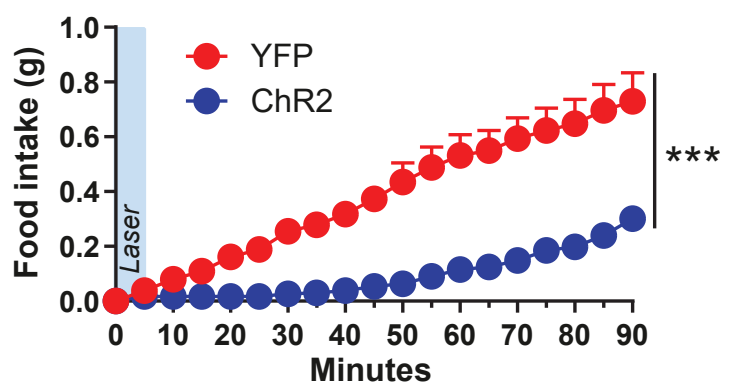

e

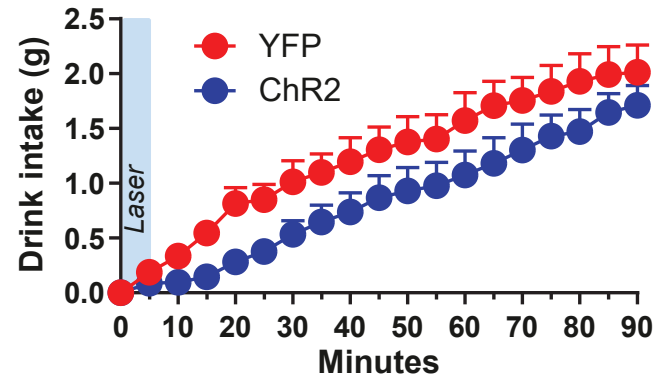

g

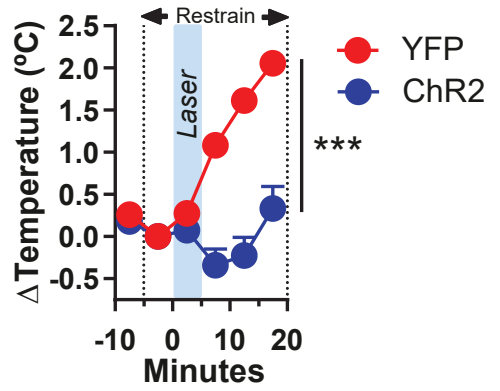


a

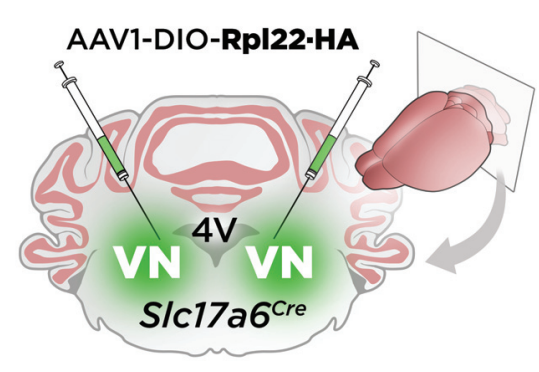

c
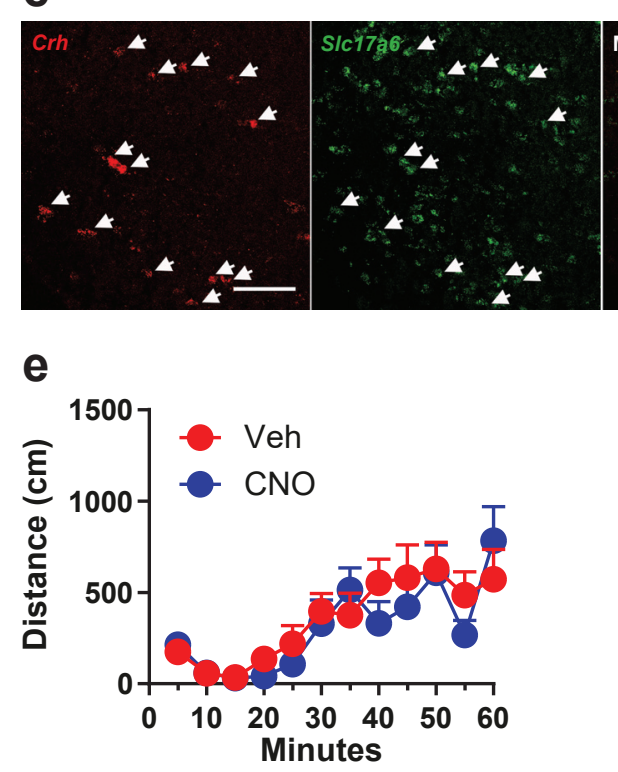

g

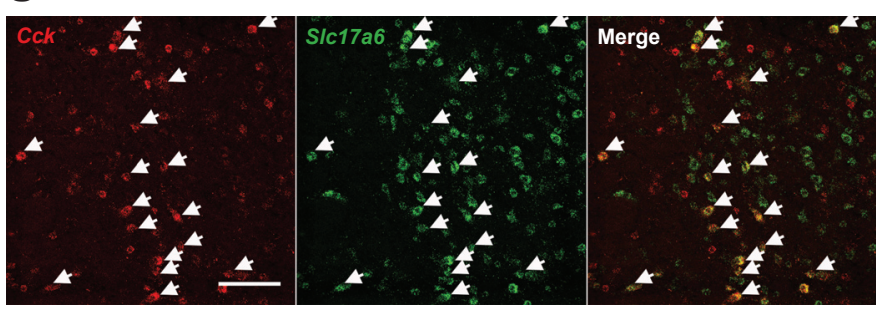

i
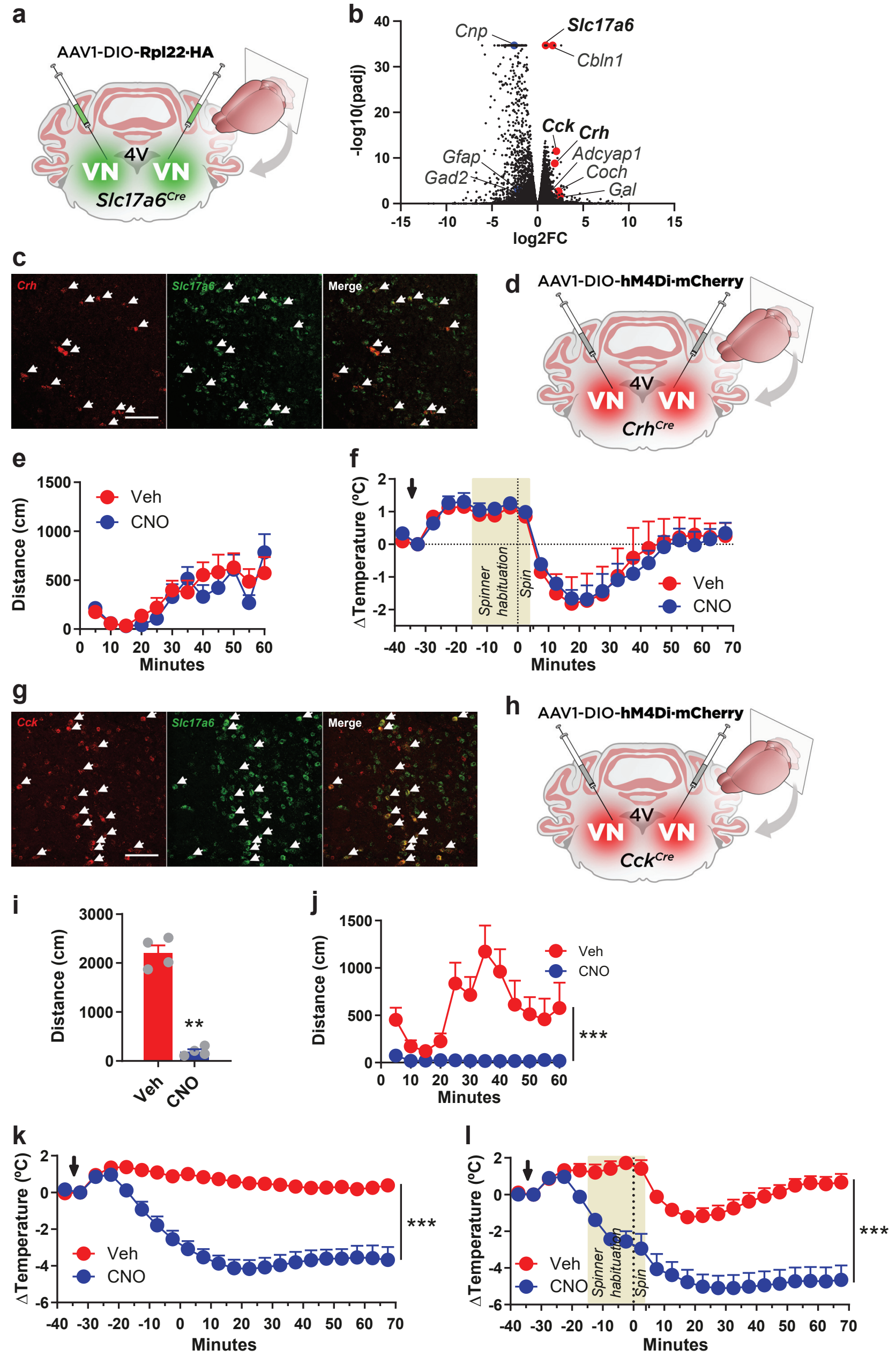

h AAV1-DIO-hM4Di-mCherry
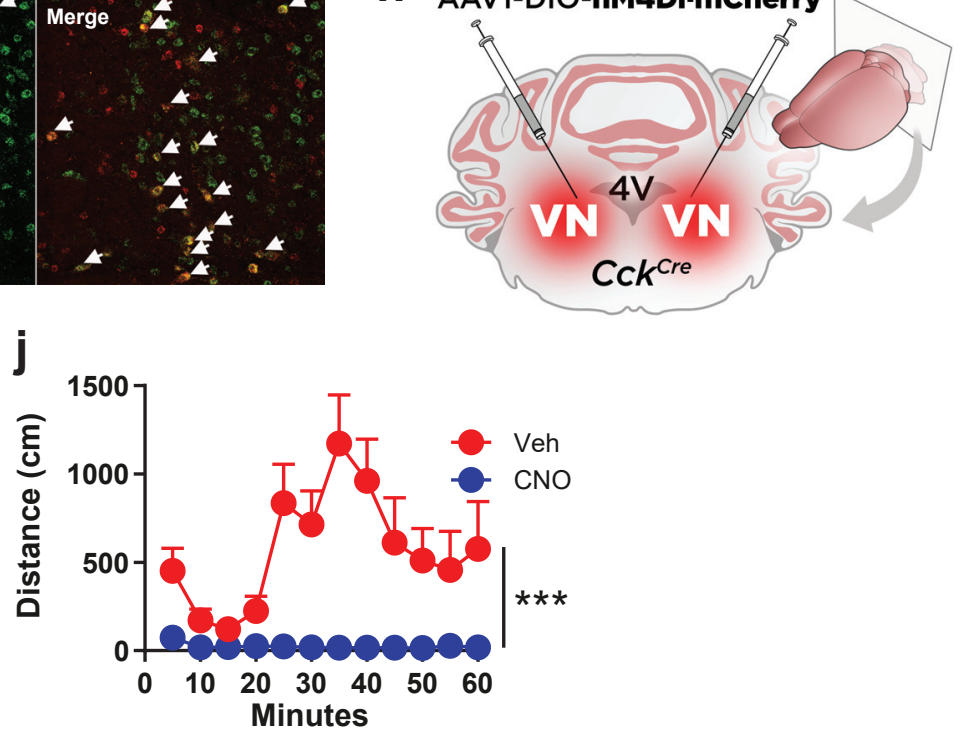

Fig. 3 
Fig. 4

a

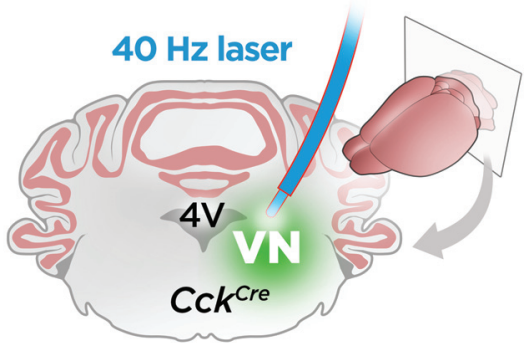

d

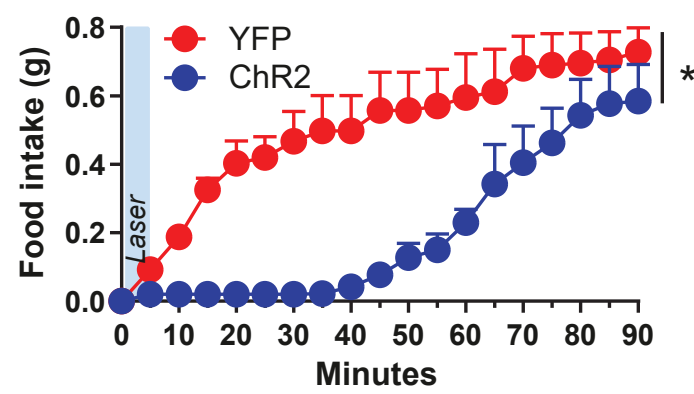

C
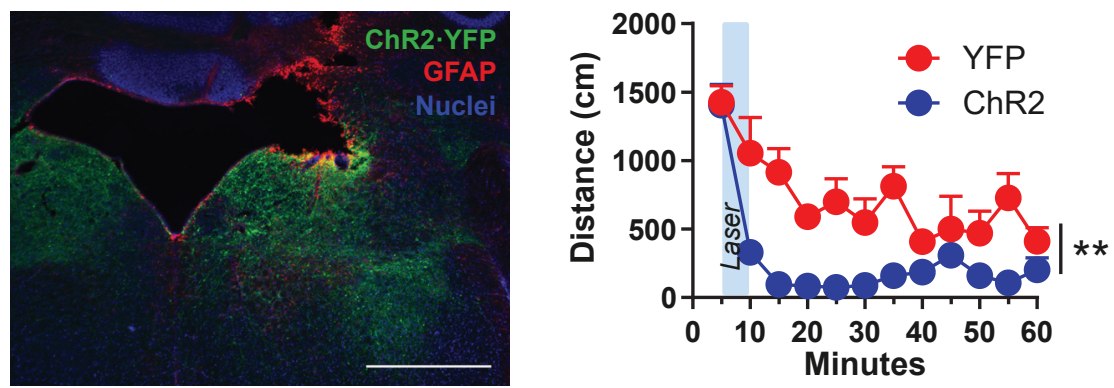

e

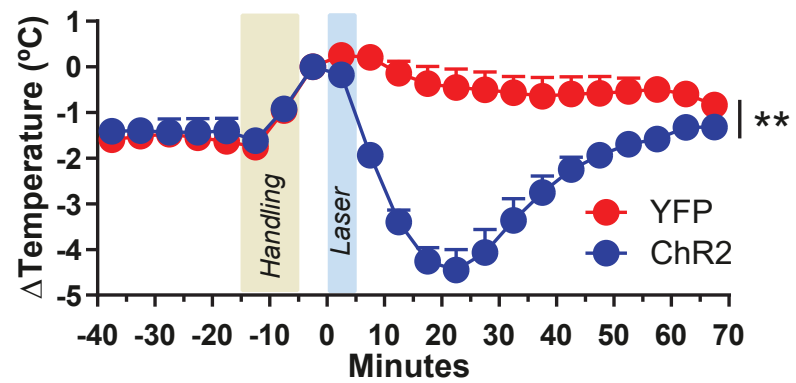


Fig. 5

a

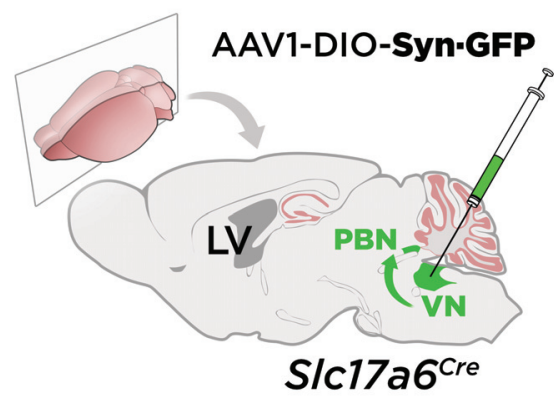

C

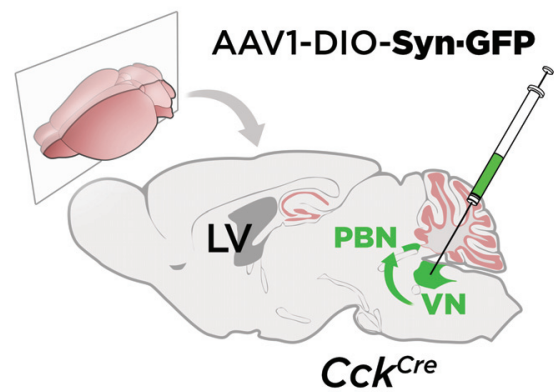

e

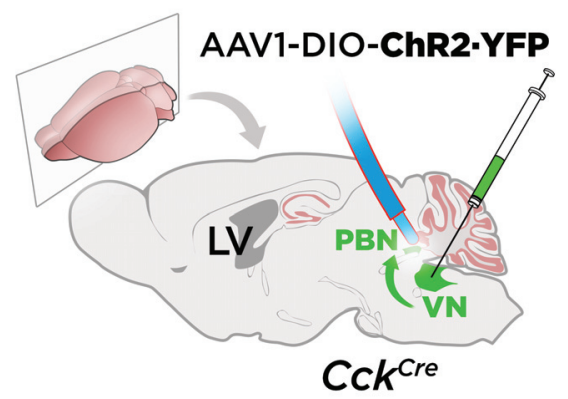

g

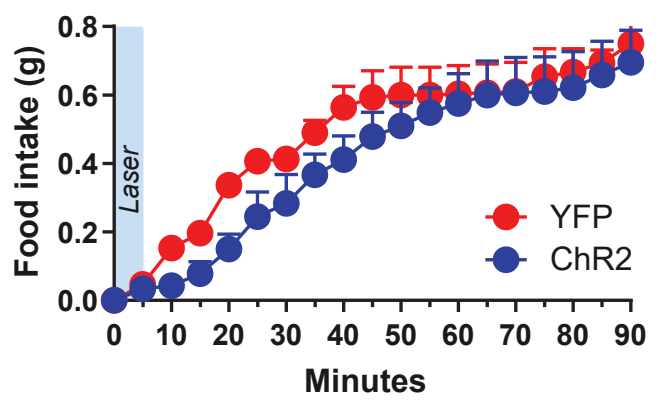

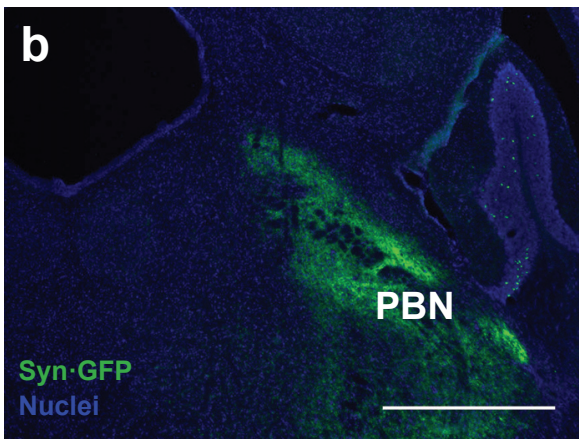

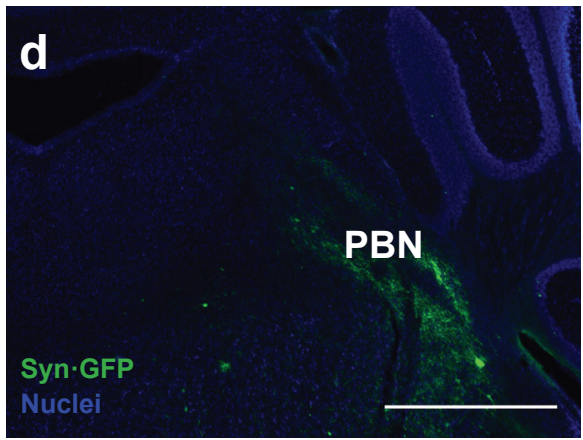

\section{f}

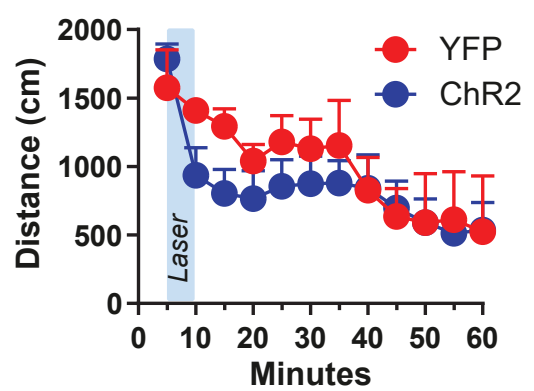

h

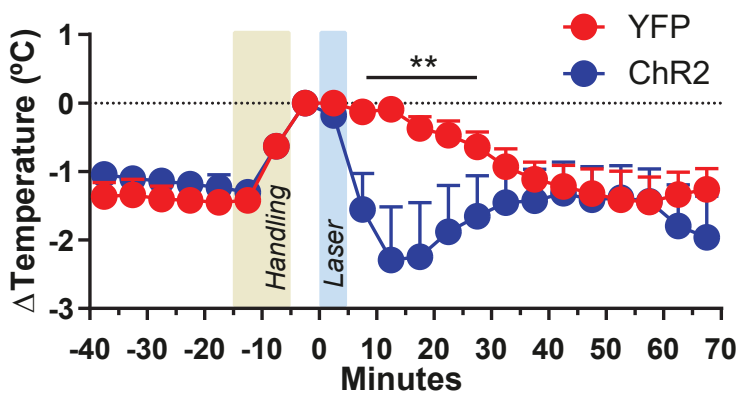


Fig. 6

a

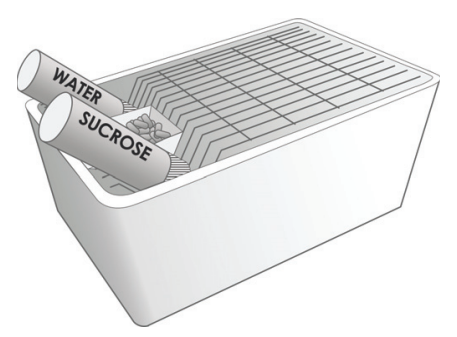

C Photostimulation $\left(\mathrm{CCK}^{\mathrm{VN}}\right)$

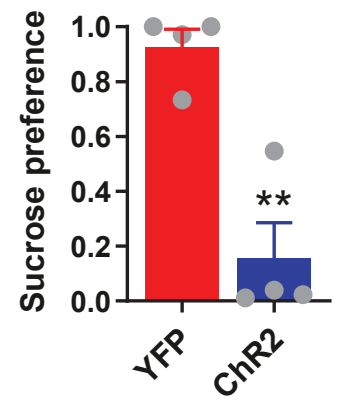

e
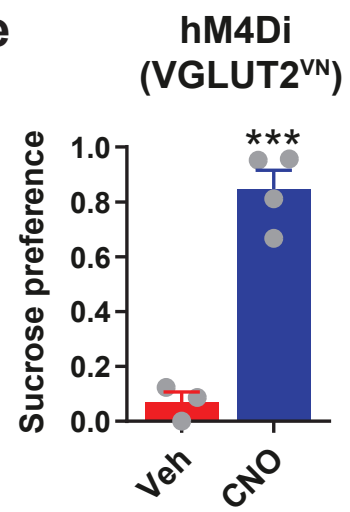

g

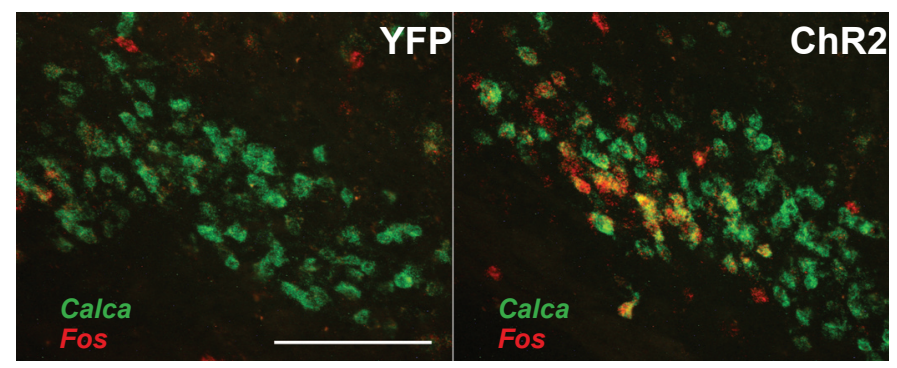

b

Spin

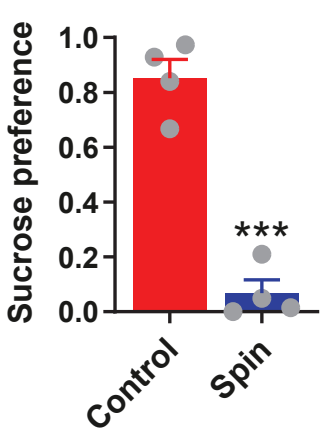

d Photostimulation

(CCK ${ }^{\mathrm{VN}->\mathrm{PBN}}$ )

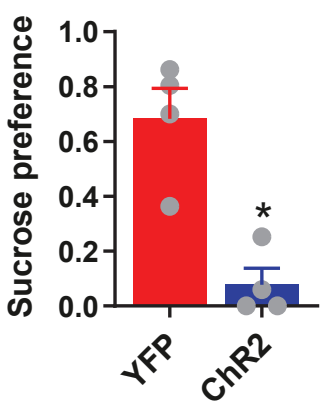

f Photostimulation

(VGLUT2 ${ }^{\mathrm{VN}}$ )

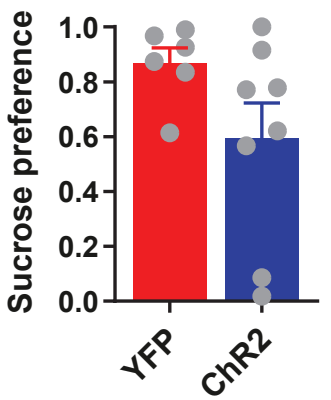


Fig. 7

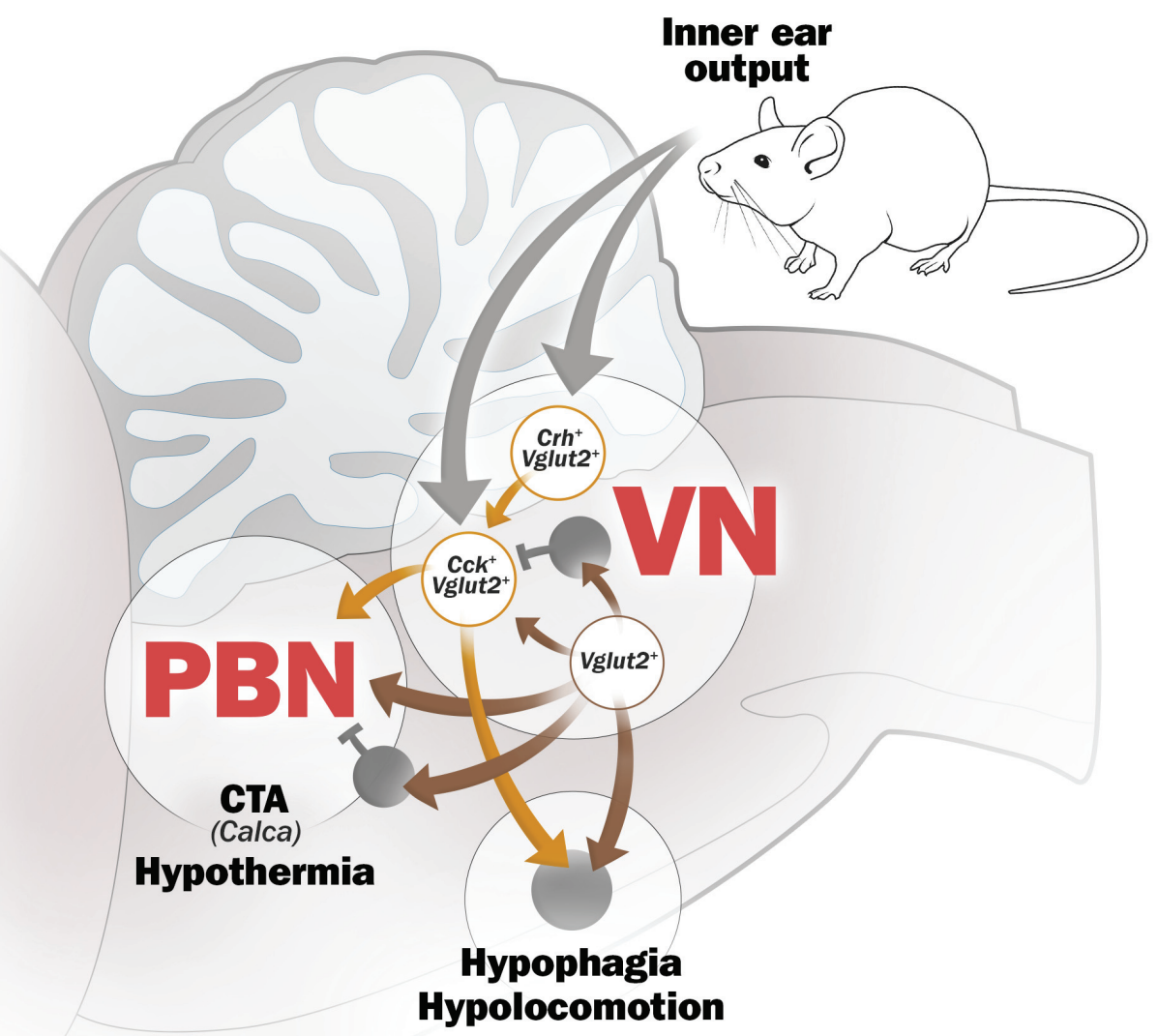


a

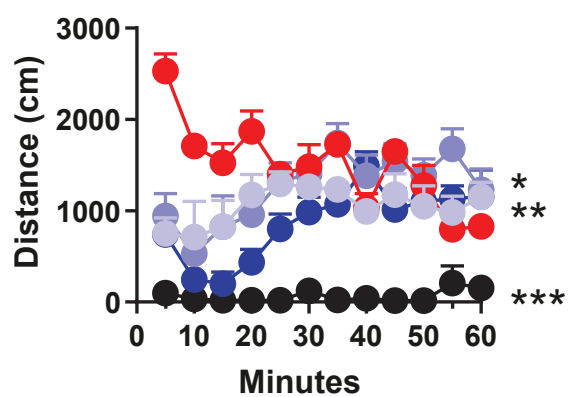

b

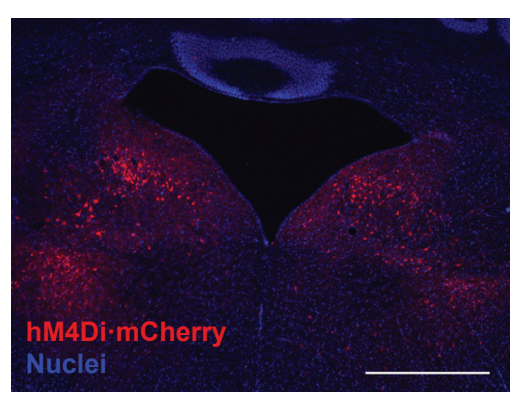

Extended Data Fig. 1

$0 \mathrm{~g}, 4 \mathrm{~min}$

$3 \mathrm{~g}, 1 \mathrm{~min} \times 2$

$3 \mathrm{~g}, 1 \mathrm{~min} \times 4$

$4 \mathrm{~g}, 1 \mathrm{~min} \times 4$

$12 \mathrm{~g}, 1 \mathrm{~min} \times 2+$ $4 \mathrm{~g}, 1 \mathrm{~min} \times 3$
C

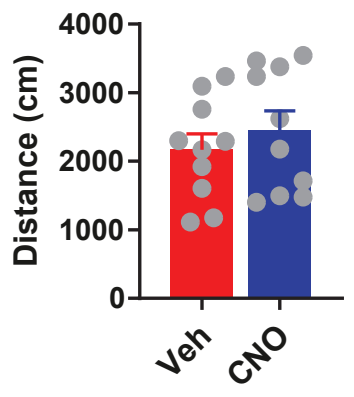


Extended Data Fig. 2

a

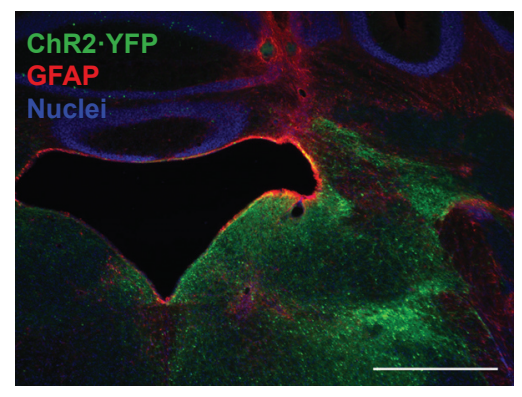

b

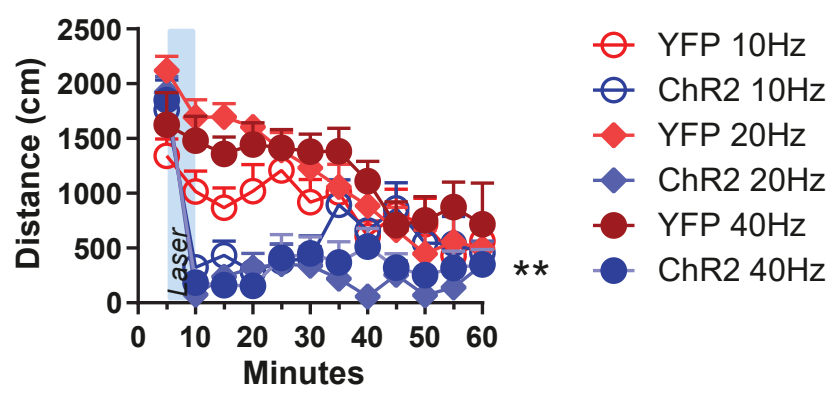


a

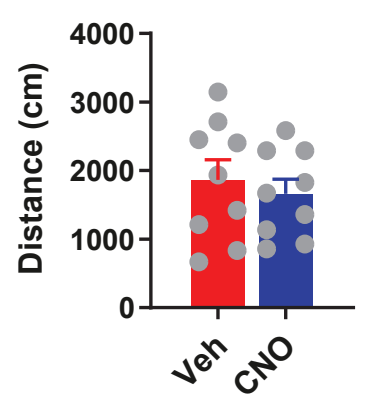

C

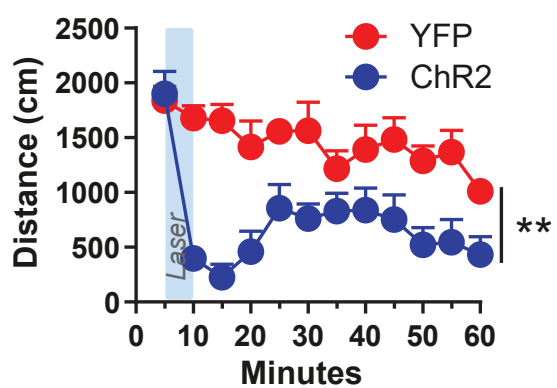

b

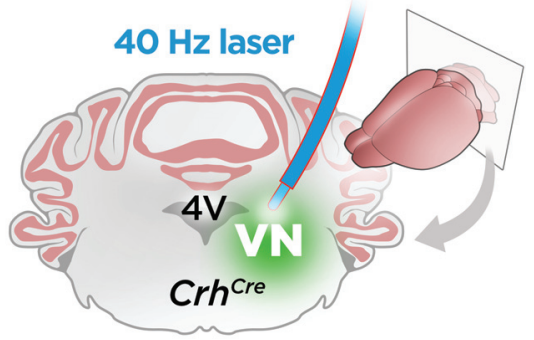

d

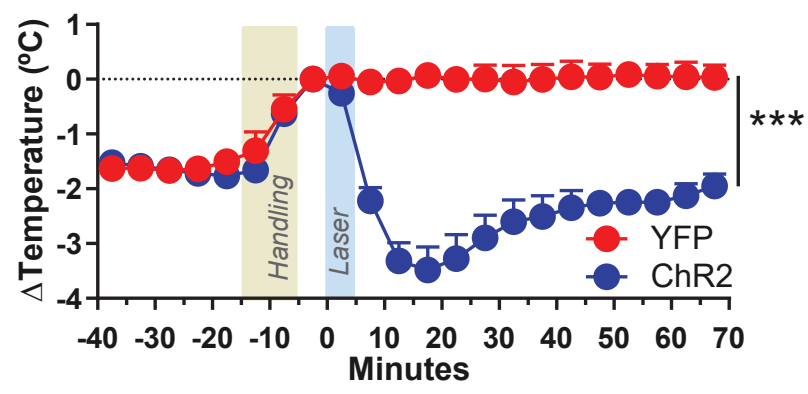

Extended Data Fig. 3 
bioRxiv preprint doi: https://doi.org/10.1101/2021.09.08.459510; this version posted September 10, 2021. The copyright holder for this preprint (which was not certified by peer review) is the author/funder, who has granted bioRxiv a license to display the preprint in perpetuity. It is made available under aCC-BY-NC-ND 4.0 International license.

Extended data Fig. 4

a

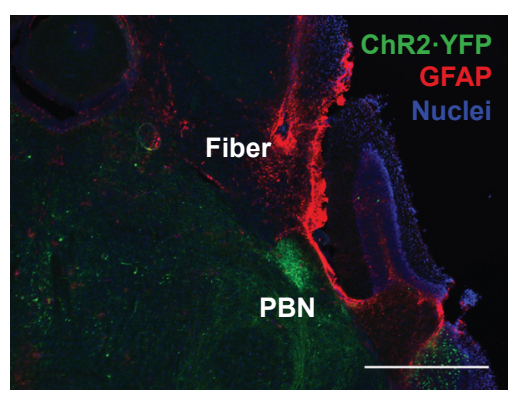

b

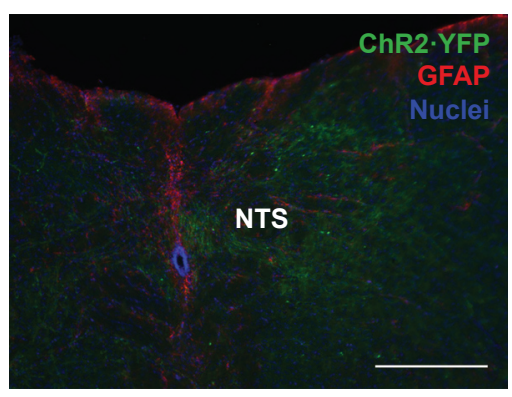


bioRxiv preprint doi: https://doi.org/10.1101/2021.09.08.459510; this version posted September 10, 2021. The copyright holder for this preprint (which was not certified by peer review) is the author/funder, who has granted bioRxiv a license to display the preprint in perpetuity. It is made available under aCC-BY-NC-ND 4.0 International license.

Extended Data Fig. 5

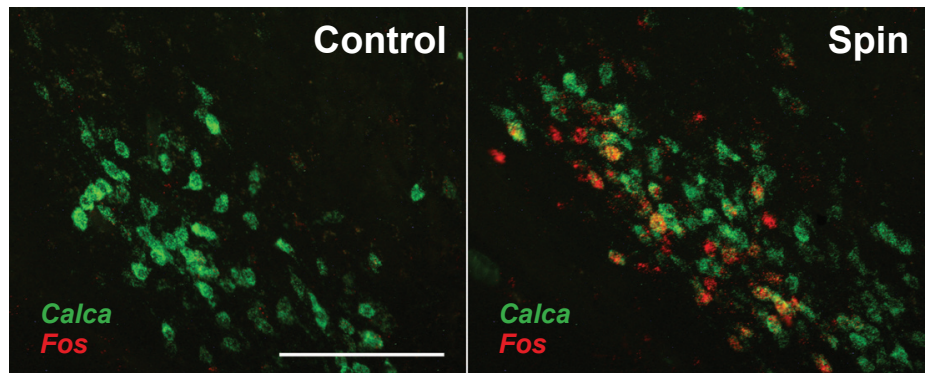

